Cochrane Database of Systematic Reviews

\title{
Exhaled nitric oxide levels to guide treatment for adults with asthma (Review)
}

Petsky HL, Kew KM, Turner C, Chang AB

Petsky HL, Kew KM, Turner C, Chang AB.

Exhaled nitric oxide levels to guide treatment for adults with asthma.

Cochrane Database of Systematic Reviews 2016, Issue 9. Art. No.: CD011440.

DOI: 10.1002/14651858.CD011440.pub2.

www.cochranelibrary.com 
TABLE OF CONTENTS

HEADER 1

ABSTRACT

PLAIN LANGUAGE SUMMARY

SUMMARY OF FINDINGS

BACKGROUND

OBJECTIVES

METHODS

Figure 1.

RESULTS

Figure 2.

DISCUSSION

Figure 3.

AUTHORS' CONCLUSIONS

ACKNOWLEDGEMENTS

REFERENCES

CHARACTERISTICS OF STUDIES

DATA AND ANALYSES

Analysis 1.1. Comparison 1 Asthma treatment tailored on FeNO versus clinical symptoms, Outcome 1 Number of participants who had $\geq 1$ exacerbations over study period.

Analysis 1.2. Comparison 1 Asthma treatment tailored on FeNO versus clinical symptoms, Outcome 2 Number of exacerbations per 52 weeks (exacerbation rates).

Analysis 1.3. Comparison 1 Asthma treatment tailored on FeNO versus clinical symptoms, Outcome 3 Severe exacerbations requiring oral corticosteroids.

Analysis 1.4. Comparison 1 Asthma treatment tailored on FeNO versus clinical symptoms, Outcome 4 Severe exacerbations requiring hospitalisation.

Analysis 1.5. Comparison 1 Asthma treatment tailored on FeNO versus clinical symptoms, Outcome 5 FEV1\% pred at final visit.

Analysis 1.6. Comparison 1 Asthma treatment tailored on FeNO versus clinical symptoms, Outcome 6 FeNO level at final visit.

Analysis 1.7. Comparison 1 Asthma treatment tailored on FeNO versus clinical symptoms, Outcome 7 Symptom score as per Asthma Control Test.

Analysis 1.8. Comparison 1 Asthma treatment tailored on FeNO versus clinical symptoms, Outcome 8 Symptom score as per AQLQ.

Analysis 1.9. Comparison 1 Asthma treatment tailored on FeNO versus clinical symptoms, Outcome 9 ICS dose at final visit (microgram per day).

Analysis 1.10. Comparison 1 Asthma treatment tailored on FeNO versus clinical symptoms, Outcome 10 Subgroup (control guideline use): Number of participants who had $\geq 1$ exacerbations over study period.

Analysis 1.11. Comparison 1 Asthma treatment tailored on FeNO versus clinical symptoms, Outcome 11 Subgroup (control guideline use): Number of exacerbations per 52 weeks (exacerbation rates).

ADDITIONAL TABLES

APPENDICES

CONTRIBUTIONS OF AUTHORS

DECLARATIONS OF INTEREST

SOURCES OF SUPPORT

DIFFERENCES BETWEEN PROTOCOL AND REVIEW 
[Intervention Review]

\section{Exhaled nitric oxide levels to guide treatment for adults with asthma}

Helen L Petsky ${ }^{1}$, Kayleigh M Kew² ${ }^{2}$ Cathy Turner ${ }^{3}$, Anne B Chang ${ }^{1,4}$

1 Institute of Health and Biomedical Innovation, Queensland University of Technology, Brisbane, Australia. 2Population Health Research Institute, St George's, University of London, London, UK. ${ }^{3}$ School of Nursing, Midwifery \& Social Work, The University of Queensland, Brisbane, Australia. ${ }^{4}$ Child Health Division, Menzies School of Health Research, Charles Darwin University, Darwin, Australia

Contact address: Helen L Petsky, Institute of Health and Biomedical Innovation, Queensland University of Technology, Brisbane, Queensland, Australia. helenpetsky@gmail.com.

Editorial group: Cochrane Airways Group.

Publication status and date: New, published in Issue 9, 2016.

Citation: Petsky HL, Kew KM, Turner C, Chang AB. Exhaled nitric oxide levels to guide treatment for adults with asthma. Cochrane Database of Systematic Reviews 2016, Issue 9. Art. No.: CD011440. DOI: 10.1002/14651858.CD011440.pub2.

Copyright @ 2016 The Cochrane Collaboration. Published by John Wiley \& Sons, Ltd.

\section{A B S T R A C T}

\section{Background}

Asthma guidelines aim to guide health practitioners to optimise treatment for patients so as to minimise symptoms, improve or maintain good lung function, and prevent acute exacerbations or flare-ups. The principle of asthma guidelines is based on a step-up or stepdown regimen of asthma medications to maximise good health outcomes using minimum medications. Asthma maintenance therapies reduce airway inflammation that is usually eosinophilic. Tailoring asthma medications in accordance with airway eosinophilic levels may improve asthma outcomes such as indices of control or reduce exacerbations or both. Fractional exhaled nitric oxide (FeNO) is a marker of eosinophilic inflammation, and as it is easy to measure, has an advantage over other measurements of eosinophilic inflammation (for example sputum eosinophils).

\section{Objectives}

To evaluate the efficacy of tailoring asthma interventions based on exhaled nitric oxide (FeNO), in comparison to not using FeNO, that is management based on clinical symptoms (with or without spirometry/peak flow) or asthma guidelines or both, for asthma-related outcomes in adults.

\section{Search methods}

We searched the Cochrane Airways Group Specialised Register of Trials, the Cochrane Central Register of Controlled Trials (CENTRAL), MEDLINE, EMBASE, and reference lists of articles. The last searches were undertaken in June 2016.

\section{Selection criteria}

All randomised controlled trials (RCTs) comparing adjustment of asthma medications based on exhaled nitric oxide levels compared to not using FeNO, that is management based on clinical symptoms (with or without spirometry/peak flow) or asthma guidelines or both.

\section{Data collection and analysis}

We reviewed results of searches against predetermined criteria for inclusion. We independently selected relevant studies in duplicate. Two review authors independently assessed trial quality and extracted data. We contacted study authors for further information, receiving responses from four.

\section{Main results}

We included seven adult studies; these studies differed in a variety of ways including definition of asthma exacerbations, FeNO cutoff levels used ( 15 to $35 \mathrm{ppb}$ ), the way in which FeNO was used to adjust therapy, and duration of study (4 to 12 months). Of 1700 randomised participants, 1546 completed the trials. The mean ages of the participants ranged from 28 to 54 years old. The inclusion criteria for the 
participants in each study varied, but all had a diagnosis of asthma and required asthma medications. In the meta-analysis, there was a significant difference in the primary outcome of asthma exacerbations between the groups, favouring the FeNO group. The number of people having one or more asthma exacerbations was significantly lower in the FeNO group compared to the control group (odds ratio (OR) $0.60,95 \%$ confidence interval (Cl) 0.43 to 0.84 ). The number needed to treat to benefit (NNTB) over 52 weeks was 12 (95\% $\mathrm{Cl} 8$ to 32 ). Those in the FeNO group were also significantly more likely to have a lower exacerbation rate than the controls (rate ratio $0.59,95 \% \mathrm{Cl}$ 0.45 to 0.77 ). However, we did not find a difference between the groups for exacerbations requiring hospitalisation $(\mathrm{OR} 0.14,95 \% \mathrm{Cl} 0.01$ to 2.67 ) or rescue oral corticosteroids (OR $0.86,95 \% \mathrm{Cl} 0.50$ to 1.48 ). There was also no significant difference between groups for any of the secondary outcomes ( $\mathrm{FEV}_{1}$, FeNO levels, symptoms scores, or inhaled corticosteroid doses at final visit).

We considered three included studies that had inadequate blinding to have a high risk of bias. However, when these studies were excluded from the meta-analysis, the difference between the groups for the primary outcomes (exacerbations) remained statistically significant. The GRADE quality of the evidence ranged from moderate (for the outcome 'exacerbations') to very low (for the outcome 'inhaled corticosteroid dose at final visit') based on the lack of blinding and statistical heterogeneity. Six of the seven studies were industry supported, but the company had no role in the study design or data analyses.

\section{Authors' conclusions}

With new studies included since the last version of this review, which included adults and children, this updated meta-analysis in adults with asthma showed that tailoring asthma medications based on FeNO levels (compared with primarily on clinical symptoms) decreased the frequency of asthma exacerbations but did not impact on day-to-day clinical symptoms, end-of-study FeNO levels, or inhaled corticosteroid dose. Thus, the universal use of FeNO to help guide therapy in adults with asthma cannot be advocated. As the main benefit shown in the studies in this review was a reduction in asthma exacerbations, the intervention may be most useful in adults who have frequent exacerbations. Further RCTs encompassing different asthma severity, ethnic groups in less affluent settings, and taking into account different FeNO cutoffs are required.

\section{PLAIN LANGUAGE SUMMARY}

\section{Exhaled nitric oxide to guide asthma treatment for adults}

\section{Background}

We examined whether exhaled nitric oxide (a marker in the breath which can show a type of lung inflammation) is useful in adjusting asthma medications in adults in comparison to the usual ways that asthma medications are adjusted. Exhaled nitric oxide levels are easily obtained by getting the person to breathe into a commercially available analyser.

\section{Study characteristics}

We included all randomised controlled trials that compared adjustment of asthma medications by usual clinical care (control group) versus using exhaled nitric oxide. The participants included in the trials had asthma diagnosed as per relevant asthma guidelines.

The evidence is current to June 2016, when the searches were last completed.

We found seven studies in the searches. Of 1700 randomised participants, 1546 completed the trials. The studies varied in a few aspects including duration, cutoff levels used for altering medications based on fractional exhaled nitric oxide (FeNO), and the way each study defined exacerbations. The included studies ranged from 4 months to 12 months in duration. The FeNO cutoff values the studies used also varied. The levels used for decreasing medications ranged from $10 \mathrm{ppb}$ to $25 \mathrm{ppb}$. Likewise, the levels used for increasing medications ranged from $15 \mathrm{ppb}$ to $35 \mathrm{ppb}$ in the included studies. The majority of the studies were industry supported.

The mean ages of the participants ranged from 28 to 54 years old.

\section{Key results}

In this review involving 1700 adults with asthma, we found that guiding the dose of asthma medications based on exhaled nitric oxide (compared to a control group) was beneficial in reducing the number of exacerbations (flare-ups) during the study period. However, we did not find a difference between groups for other asthma outcomes that impact on day-to-day clinical symptoms, hospitalisations, or inhaled steroid dose. Thus, using exhaled nitric oxide levels to adjust asthma therapy may reduce the risk of adults having an asthma flareup but did not impact on day-to-day symptoms.

\section{Quality of the evidence}

The quality of evidence ranged from moderate when comparing the two groups for the exacerbation outcomes, to very low when comparing the groups for inhaled corticosteroid dose at final visit. 


\begin{tabular}{|c|c|c|c|c|c|c|}
\hline \multicolumn{7}{|c|}{$\begin{array}{l}\text { S U M M A R Y O F F I N D I N G S } \\
\text { Summary of findings for the main comparison. Tailoring asthma treatment using FeNO versus clinical symptoms }\end{array}$} \\
\hline \multicolumn{7}{|c|}{ Tailoring asthma treatment using FeNO versus clinical symptoms } \\
\hline \multicolumn{7}{|c|}{$\begin{array}{l}\text { Patient or population: adults with asthma } \\
\text { Setting: outpatient } \\
\text { Intervention: asthma treatment tailored on FeNO } \\
\text { Comparison: asthma treatment tailored on clinical symptoms }\end{array}$} \\
\hline \multirow[t]{2}{*}{ Outcomes } & \multicolumn{2}{|c|}{ Anticipated absolute effects ${ }^{\star}(95 \% \mathrm{Cl})$} & \multirow{2}{*}{$\begin{array}{l}\text { Relative effect } \\
(95 \% \mathrm{Cl})\end{array}$} & \multirow{2}{*}{$\begin{array}{l}\text { No of partici- } \\
\text { pants } \\
\text { (studies) }\end{array}$} & \multirow{2}{*}{$\begin{array}{l}\text { Quality of the } \\
\text { evidence } \\
\text { (GRADE) }\end{array}$} & \multirow[t]{2}{*}{ Comments } \\
\hline & $\begin{array}{l}\text { Risk with asthma treat- } \\
\text { ment tailored on clinical } \\
\text { symptoms }\end{array}$ & $\begin{array}{l}\text { Risk with asthma treat- } \\
\text { ment tailored on FeNO }\end{array}$ & & & & \\
\hline $\begin{array}{l}\text { Number of participants who } \\
\text { had } \geq 1 \text { exacerbations over } \\
\text { study period } \\
\text { Follow-up: range } 18 \text { weeks to } 52 \\
\text { weeks }\end{array}$ & 25 per 100 & $\begin{array}{l}\mathbf{1 7} \text { per } 100 \\
\text { (13 to } 22)\end{array}$ & $\begin{array}{l}\text { OR } 0.60 \text { (0.43 to } \\
0.84)\end{array}$ & $\begin{array}{l}1005 \\
\text { (5 RCTs) }\end{array}$ & $\begin{array}{l}\oplus \oplus \oplus \ominus \\
\text { MODERATE } 1\end{array}$ & - \\
\hline $\begin{array}{l}\text { Number of exacerbations per } \\
\mathbf{5 2} \text { weeks (exacerbation rates) } \\
\text { Follow-up: mean } 52 \text { weeks }\end{array}$ & $\begin{array}{l}\text { The control group ranged } \\
\text { from } 0.23 \text { to } 0.9 \text { exacerba- } \\
\text { tions per } 52 \text { weeks }\end{array}$ & $\begin{array}{l}\text { Rate ratio } 0.59 \text { ( } 0.45 \text { to } \\
0.77 \text { ) }\end{array}$ & - & $\begin{array}{l}842 \\
\text { (5 RCTs) }\end{array}$ & $\begin{array}{l}\oplus \oplus \oplus \ominus \\
\text { MODERATE } 1\end{array}$ & - \\
\hline $\begin{array}{l}\text { ICS dose at final visit } \\
\text { Follow-up: range } 18 \text { weeks to } 52 \\
\text { weeks }\end{array}$ & $\begin{array}{l}\text { The mean ICS dose taken } \\
\text { by the control group at final } \\
\text { visit was } \\
\mathbf{6 5 9} \mathbf{~ m c g}\end{array}$ & $\begin{array}{l}\text { The mean ICS dose taken } \\
\text { in the FeNO groups was } \\
17.01 \text { lower ( } 101.75 \text { lower } \\
\text { to } 67.72 \text { more) } \mathbf{5 7 7} \mathbf{~ m c g}\end{array}$ & - & $\begin{array}{l}582 \\
\text { (4 RCTs) }\end{array}$ & $\begin{array}{l}\oplus \oplus \Theta \odot \\
\text { VERY LOW2,3 }\end{array}$ & $\begin{array}{l}\text { A random-ef- } \\
\text { fects sensitivi- } \\
\text { ty analysis gave } \\
\text { a very impre- } \\
\text { cise result: MD } \\
-147.15(95 \% \\
\text { Cl -380.85 to } \\
86.56)\end{array}$ \\
\hline
\end{tabular}

${ }^{*}$ The risk in the intervention group (and its $95 \% \mathrm{Cl}$ ) is based on the assumed risk in the comparison group and the relative effect of the intervention (and its $95 \% \mathrm{Cl}$ ).

** The control group risks were calculated as a mean of the scores or events in the control groups of the studies contributing to each analysis. We could not calculate a con-

trol risk for the number of exacerbations per 52 weeks because we did not have information for each arm of the studies, just ratios between them.

CI: confidence interval; FeNO: fractional exhaled nitric oxide; ICS: inhaled corticosteroids; MD: mean difference; OR: odds ratio; RCT: randomised controlled trial

GRADE Working Group grades of evidence

High quality: We are very confident that the true effect lies close to that of the estimate of the effect 
Moderate quality: We are moderately confident in the effect estimate: The true effect is likely to be close to the estimate of the effect, but there is a possibility that it is substantially different

Low quality: Our confidence in the effect estimate is limited: The true effect may be substantially different from the estimate of the effect

Very low quality: We have very little confidence in the effect estimate: The true effect is likely to be substantially different from the estimate of effect

${ }^{1}$ Two studies, Honkoop 2014 and Syk 2013, carrying 36\% of the analysis weight, were at high risk of performance and detection bias due to lack of blinding. There were several uncertainties across studies, particularly with regard to the control of selection bias (one downgrade for risk of bias).

${ }^{2}$ Final inhaled corticosteroid doses were quite varied, with one study having particularly high doses ( 360 to 1282 in the control groups and 423 to 740 in the FeNO groups). There was substantial statistical heterogeneity in the analysis $(\mathrm{I}=82 \% ; \mathrm{P}=0.0007)$. A random-effects sensitivity analysis changed the result substantially to $\mathrm{MD}-147.15(95 \% \mathrm{Cl}-380.85$ to 86.56$)$ (one downgrade for heterogeneity, one downgrade for imprecision).

3 One study carrying $51 \%$ of the analysis weight, Syk 2013, was open labelled, which may have introduced bias (one downgrade for risk of bias). 


\section{B A C K G R O U N D}

\section{Description of the condition}

Asthma guidelines aim to guide health practitioners to optimise treatment for patients so as to minimise symptoms, optimise lung function, and prevent acute exacerbations (BTS/SIGN 2014; GINA 2014; National Asthma Council 2014). Exacerbations cause anxiety to patients and their families and are costly to healthcare systems (Weiss 2001), which puts stress on healthcare providers. Preventing exacerbations is thus an important component for maintaining ideal asthma control. The second component in asthma management is monitoring of asthma control (by subjective and objective measures) (BTS/SIGN 2014; GINA 2014; National Asthma Council 2014). Subjective measures usually involve a series of questions used for clinical assessment, diary cards, and quality of life questionnaires. Traditional objective methods include peak flow, spirometry, and degree of airway hyperresponsiveness (Zacharasiewicz 2005). Newer, and arguably more sensitive, methods include measurement of airway inflammation such as airway cellularity in induced sputum or fractional exhaled nitric oxide (FeNO).

In asthma, inflammation can be eosinophilic or neutrophilic (Douwes 2002). Asthma management is arguably best tailored in accordance with the type of airway inflammation, as corticosteroids are more beneficial in eosinophilic inflammation (Wardlaw 2000), and inhaled corticosteroids (ICS) reduce exacerbations and improve symptoms and asthma control (Wardlaw 2000). There are several ways to quantify airway eosinophilic inflammation, such as determining the percentage of eosinophils in the sputum and FeNO. FeNO correlates with other markers of asthma, for example eosinophilia in induced sputum (Jatakanon 1998), and bronchial reactivity in steroid-naive patients (Dupont 1998). Induced sputum and sputum analysis is labour intensive and not widely available in non-research laboratories. Hypertonic saline, which is used to induce sputum, may also temporarily increase asthma symptoms. Measures of FeNO thus confer some advantage over measurements of sputum eosinophils. However, FeNO does not provide any data on non-eosinophilic inflammation, and the equipment required to measure FeNO is relatively expensive.

\section{Description of the intervention}

The principle of asthma management is based on a step-up or step-down regimen of asthma medications to reduce airway inflammation, control symptoms, and reduce exacerbations. Tailoring of asthma medications in accordance to airway eosinophilic levels may improve asthma control or reduce exacerbations or both. FeNO levels can be measured using commercially available analysers. These analysers vary in several ways, including methods of measurements (online or offline), complexity, their set-up, calibration procedures, sampling tube design, measuring chamber, and the way expiratory flow is controlled (Muller 2005). Stationary analysers measure FeNO by chemiluminescence, whilst portable FeNO analysers measure FeNO using electrochemistry.

\section{How the intervention might work}

As FeNO is reflective of airway eosinophilia in some circumstances, FeNO can be considered as a biomarker. For asthma, FeNO levels can potentially be used in adults with asthma to:
- monitor airway eosinophilia;

- verify the adherence to ICS; and

- predict upcoming asthma exacerbations.

Reduction of airway inflammation improves symptoms and asthma control (Wardlaw 2000). Hence, the use of FeNO levels to tailor asthma medications in adults with asthma may improve asthma control or reduce exacerbations or both.

\section{Why it is important to do this review}

A Cochrane review has previously been published combining adults and children in one review (Petsky 2009). Given the clinical heterogeneity between children and adults with asthma, we undertook separate reviews for children and adults for the updates. Hence this is a new review, but is based on our previously published review (Petsky 2009). This review focuses on adults, and there will be a similar systematic review that includes only children as participants (Petsky 2015b).

A systematic review evaluating the efficacy of tailoring asthma interventions based on FeNO levels in comparison with not using FeNO (that is the traditional reliance upon clinical symptoms or following asthma guidelines with or without spirometry/peak flow) will be useful to guide clinical practice in adults with asthma. Using FeNO routinely in clinical practice adds to the burden of asthma care and resource utilisation. On the other hand, routine use of FeNO may improve asthma control and reduce exacerbations and hospitalisations related to asthma.

\section{O B JECTIVES}

To evaluate the efficacy of tailoring asthma interventions based on exhaled nitric oxide (FeNO) in comparison to not using FeNO, that is management based on clinical symptoms (with or without spirometry/peak flow) or asthma guidelines or both for asthmarelated outcomes in adults.

\section{METHODS}

\section{Criteria for considering studies for this review}

\section{Types of studies}

We included randomised controlled trials (RCTs) comparing adjustment of asthma medications based on exhaled nitric oxide levels compared to those not using FeNO, that is management based on clinical symptoms (with or without spirometry/peak flow) or asthma guidelines or both. We included studies reported as full text, those published as abstract only, and unpublished data.

\section{Types of participants}

We included adults with a diagnosis of asthma according to a guideline-defined criteria.

We excluded participants with the following comorbidities/ characteristics: eosinophilic bronchitis, asthma related to an underlying lung disease such as bronchiectasis and chronic obstructive pulmonary disease (COPD), or diagnostic categories such as 'cough variant asthma' and 'wheezy bronchitis' where controversies exist. 


\section{Types of interventions}

We included RCTs comparing adjustment of asthma medications based on FeNO levels versus control groups where FeNO was not used to adjust asthma medications. Control group interventions may include use of clinical symptoms (with or without spirometry/ peak flow) or asthma guidelines or both to guide adjustment of asthma medications. We included studies in which other interventions were used if all participants had equal access to such interventions. We included studies of at least 12 weeks' duration.

\section{Types of outcome measures}

\section{Primary outcomes}

Asthma exacerbations during follow-up, with the following definitions.

1. Number of participants who had one or more exacerbations over the study period.

2. Number of exacerbations per 52 weeks (exacerbation rate).

3. Severe exacerbations requiring oral corticosteroids.

4. Severe exacerbation requiring hospitalisation.

\section{Secondary outcomes}

1. Objective measurements of asthma control $\left(\mathrm{FEV}_{1}\right.$, peak flow, airway hyper-responsiveness).

2. FeNO level.

3. Symptoms of asthma as reported in Asthma Control Test.

4. Symptoms of asthma as reported in asthma-related quality of life questionnaire score (AQLQ).

5. Inhaled corticosteroid dose at final visit.

Reporting one or more of the outcomes listed here in the study was not an inclusion criterion for the review.

\section{Search methods for identification of studies}

\section{Electronic searches}

We identified trials from the Cochrane Airways Group's Specialised Register (CAGR), which is maintained by the Information
Specialist for the Group. The Register contains trial reports identified through systematic searches of bibliographic databases including the Cochrane Central Register of Controlled Trials (CENTRAL), MEDLINE, EMBASE, CINAHL, AMED, and PsycINFO, and handsearching of respiratory journals and meeting abstracts (please see Appendix 1 for further details). We searched all records in the CAGR using the search strategy in Appendix 2.

We also conducted a search of ClinicalTrials.gov (www.ClinicalTrials.gov) and the WHO trials portal (www.who.int/ ictrp/en/), using the search strategy in Appendix 3. We searched all databases from their inception to June 2016, and we imposed no restriction on language of publication.

\section{Searching other resources}

We checked reference lists of all primary studies and review articles for additional references. We searched relevant manufacturers' websites for trial information.

We searched for errata or retractions from included studies published in full text on PubMed (www.ncbi.nlm.nih.gov/pubmed) and reported the date this was done within the review.

\section{Data collection and analysis}

\section{Selection of studies}

Two review authors (HP, KK) independently screened the titles and abstracts of all the studies we identified as a result of the search for inclusion and coded them as 'retrieve' (eligible or potentially eligible/unclear) or 'do not retrieve'. We then retrieved the fulltext study reports/publication, and two review authors (HP, KK) independently screened the full text and identified studies for inclusion, and identified and recorded reasons for exclusion of the ineligible studies. We planned to resolve any disagreements through discussion or, if required, by consulting a third review author (AC). We identified and excluded duplicates and collated multiple reports of the same study so that each study, rather than each report, was the unit of interest in the review. We recorded the selection process in sufficient detail to complete a PRISMA flow diagram (Figure 1) and Characteristics of excluded studies table. 
Figure 1. Study flow diagram.

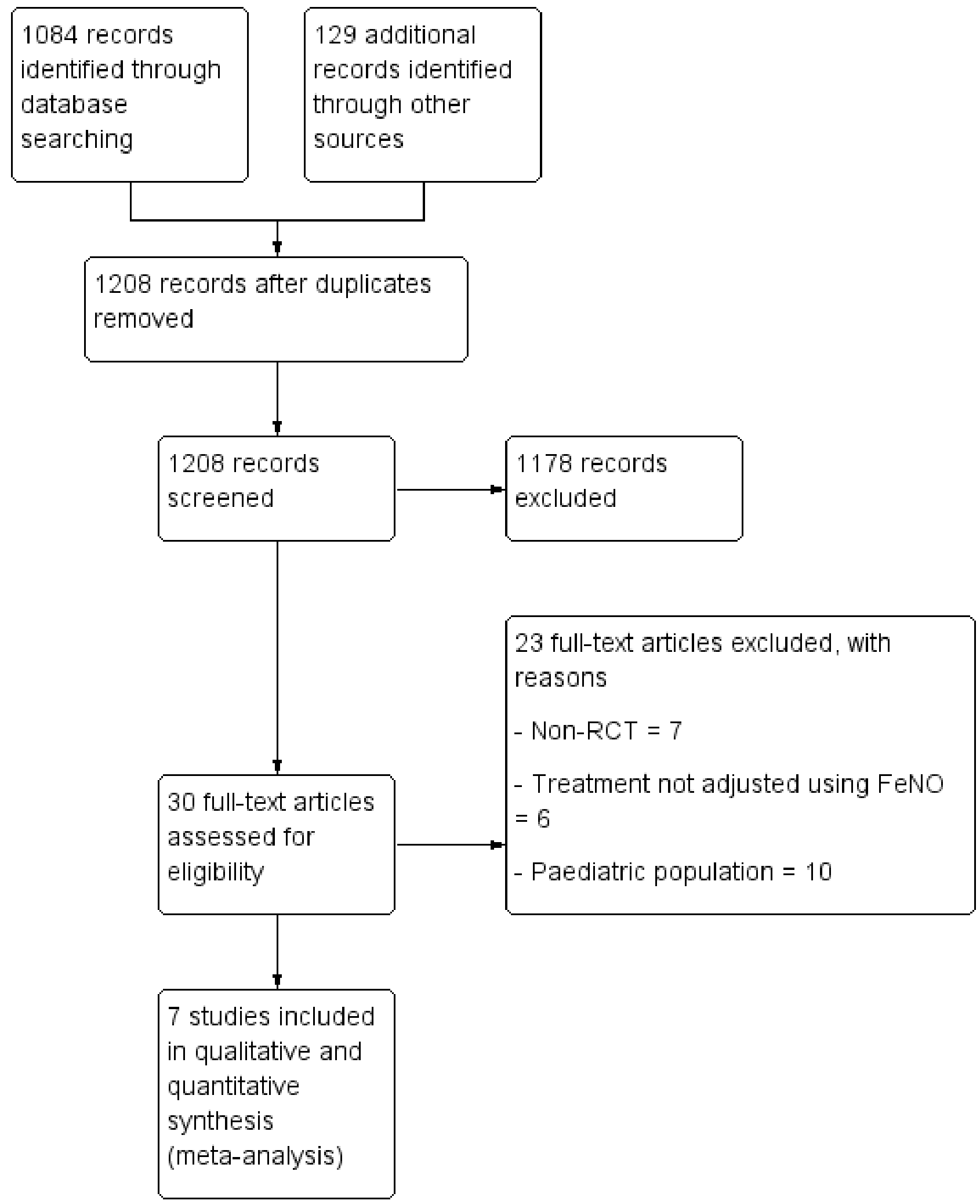

\section{Data extraction and management}

We used a data collection form for study characteristics and outcome data that had been piloted on at least one study in the review. One review author (HP) extracted study characteristics from included studies. We then extracted the following study characteristics. 
1. Methods: study design, total duration of study, details of any 'run in' period, number of study centres and location, study setting, withdrawals, and date of study.

2. Participants: N, mean age, age range, gender, severity of condition, diagnostic criteria, baseline lung function, smoking history, inclusion criteria, and exclusion criteria.

3. Interventions: intervention, comparison, concomitant medications, and excluded medications.

4. Outcomes: primary and secondary outcomes specified and collected, and time points reported.

5. Notes: funding for trial, and notable conflicts of interest of trial authors.

Two review authors (HP, KK) independently extracted outcome data from included studies from the 2015 and 2016 searches. We then noted in the Characteristics of included studies table if outcome data were not reported in a useable way. We planned to resolve disagreements by consensus or by involving a third review author (AC). One review author (HP) transferred data into the RevMan 2014 file. We double-checked that data had been entered correctly by comparing the data presented in the systematic review with the study reports. A second review author (KK) checked the study characteristics for accuracy against the trial report.

\section{Assessment of risk of bias in included studies}

Two review authors (HP, KK) independently assessed risk of bias for each study using the criteria outlined in the Cochrane Handbook for Systematic Reviews of Interventions (Higgins 2011). We planned to resolve any disagreements by discussion or by involving another review author (AC). We assessed the risk of bias according to the following domains.

1. Random sequence generation.

2. Allocation concealment.

3. Blinding of participants and personnel.

4. Blinding of outcome assessment.

5. Incomplete outcome data.

6. Selective outcome reporting.

7. Other bias.

We graded each potential source of bias as high, low, or unclear and provided a quote from the study report together with a justification for our judgement in the 'Risk of bias' table. We then summarised the 'Risk of bias' judgements across different studies for each of the domains listed. We planned to judge blinding separately for different key outcomes where necessary (for example for unblinded outcome assessment, risk of bias for all-cause mortality may be very different than for a patient-reported pain scale). Where information on risk of bias related to unpublished data or correspondence with a trialist, we noted this in the 'Risk of bias' table.

When considering treatment effects, we took into account the risk of bias for the studies that contributed to that outcome.

\section{Assessment of bias in conducting the systematic review}

We conducted the review according to this published protocol and reported any deviations from it in the Differences between protocol and review section of the systematic review.

\section{Measures of treatment effect}

We analysed dichotomous data as odds ratios and continuous data as mean difference or standardised mean difference. We then entered data presented as a scale with a consistent direction of effect.

We undertook meta-analyses only where it was meaningful, that is if the treatments, participants, and the underlying clinical question were similar enough for pooling to make sense.

We narratively described skewed data that was reported as medians and interquartile ranges.

Where multiple trial arms were reported in a single trial, we included only the relevant arms. If two comparisons (for example drug $A$ versus placebo and drug B versus placebo) were combined in the same meta-analysis, we halved the control group to avoid double-counting.

\section{Unit of analysis issues}

For dichotomous data, we reported the proportion of participants contributing to each outcome in comparison with the total number randomised. For rate ratios of common events whereby one participant may have more than one event, we used generic inverse variance (GIV). We took the rate ratios from the published papers and calculated the standard errors from confidence intervals $(\mathrm{Cl})$ or $P$ values published in the papers. It was planned that for cross-over studies, mean treatment differences were to be calculated from raw data, and variances extracted or imputed and entered as fixedeffect GIV outcome, to provide summary weighted differences and $95 \%$ Cls.

\section{Dealing with missing data}

We contacted investigators or study sponsors to verify key study characteristics and to obtain missing numerical outcome data where possible (for example when a study was identified as abstract only). Where this was not possible, and the missing data were thought to introduce serious bias, we explored the impact of including such studies in the overall assessment of results with a sensitivity analysis.

\section{Assessment of heterogeneity}

We described and tested any heterogeneity between study results to see if it reached statistical significance using a Chi2 test. We planned to include the $95 \% \mathrm{Cl}$ estimated using a randomeffects model whenever there was concerns about statistical heterogeneity. Heterogeneity is considered significant when the $P$ value is less than 0.10 (Higgins 2011). We then used the $\mathrm{I}^{2}$ statistic to measure heterogeneity among the trials in each analysis. If we identified substantial heterogeneity, we reported it and explored possible causes by prespecified subgroup analysis.

\section{Assessment of reporting biases}

As we were unable to pool more than 10 trials, we did not create and examine a funnel plot to explore possible small-study and publication biases.

\section{Data synthesis}

We included the results from studies that met the inclusion criteria and reported any of the outcomes of interest in the subsequent 
meta-analyses. We calculated the summary weighted risk ratio and $95 \% \mathrm{Cl}$ (fixed-effect model) (RevMan 2014). For rate ratios of common events whereby one participant had more than one event, we utilised GIV. We took the rate ratios from the published papers and calculated the standard errors from $\mathrm{Cl}$ or $\mathrm{P}$ values published in the papers. For cross-over studies, we planned to calculate mean treatment differences from raw data, and extract or impute variances and enter them as fixed-effect GIV, to provide summary weighted differences and $95 \% \mathrm{Cl}$. We calculated number needed to treat to benefit (NNTB) from the pooled odds ratio and its $95 \% \mathrm{Cl}$ applied to a specified baseline risk using an online calculator (Cates 2008). The outcome indices were assumed to be normally distributed continuous variables so the mean difference in outcomes could be estimated. If studies reported outcomes using different measurement scales, we estimated the standardised mean difference.

\section{'Summary of findings' table}

We created a 'Summary of findings' table using the following outcomes.

1. Number of participants who had one or more exacerbation over the study period.

2. Number of exacerbations per 52 weeks.

3. Inhaled corticosteroid (ICS) dose at final visit.

The 'Summary of findings' table in the previous combined review, Petsky 2009, was amended to reflect the new data and restricted to the inclusion criteria of this review. We used the five GRADE considerations (study limitations, consistency of effect, imprecision, indirectness, and publication bias) to assess the quality of a body of evidence as it relates to the studies that contributed data to the meta-analyses for the prespecified outcomes. We then used methods and recommendations described in Section 8.5 and Chapter 12 of the Cochrane Handbook for Systematic Reviews of Interventions, Higgins 2011, using GRADEpro software. We justified all decisions to down- or up-grade the quality of studies using footnotes, and we made comments to aid the reader's understanding of the review where necessary.

\section{Subgroup analysis and investigation of heterogeneity}

We planned subgroup analysis for the following.

1. Basis for adjustment of ICS in the control group (guidelinedriven monitoring versus non-guideline driven).

2. Use of spirometry or peak flow as an adjunctive monitoring tool for adjustment of medications (versus non-use of spirometry or peak flow).

3. Baseline ICS dose at commencement of intervention (lowmedium ( $<800 \mathrm{mcg} /$ day budesonide equivalent) versus high dose ( $800 \mathrm{mcg} /$ day or more budesonide equivalent)).

4. FeNO cutoffs for adjustment of medications ( $\leq 20 \mathrm{ppb}$ versus $>$ $20 \mathrm{ppb}$ ).

5. FeNO cutoffs, based on presence of atopy.

\section{Sensitivity analysis}

We carried out the following sensitivity analyses.

1. Sensitivity analysis excluding studies with a high risk of bias based on the 'Risk of bias' assessment. Studies that did not have adequate allocation concealment and sequence generation were removed.

2. Variation in the inclusion criteria. Studies that included adults not receiving ICS at recruitment were removed.

3. Differences in the medications used in the intervention and comparison group. Studies that adjusted medications only for one arm were removed.

4. Analysis that used the random-effects model.

5. Analysis that used 'strategy received'. Studies with hierarchy management protocols that only considered use of steroids for each step (i.e. without consideration for using montelukast or long-acting beta-agonist or both at any point) were removed.

\section{RES U LTS}

\section{Description of studies}

Please see: Characteristics of included studies; Characteristics of excluded studies; and Characteristics of ongoing studies.

\section{Results of the search}

The Cochrane Airways Group's Specialised Register identified 1084 potentially relevant titles from the 2015 and 2016 searches (Figure 1). We identified an additional 129 titles through searches of ClinicalTrials.gov (www.ClinicalTrials.gov) and the WHO trials portal (www.who.int/ictrp/en/). After assessing the abstracts, we obtained 30 papers for consideration after removal of duplicates. We excluded 14 papers due to non-randomisation or treatment not adjusted based on FeNO. Of the remaining 16 papers, seven papers included adult participants, and nine were based on children or adolescents, which will be presented in a separate Cochrane Review (Petsky 2015b).

\section{Included studies}

See Characteristics of included studies table.

We included seven studies involving a total of 1700 randomised participants, of which 1546 completed the trial (Calhoun 2012; Hashimoto 2011; Honkoop 2014; Powell 2011; Shaw 2007; Smith 2005; Syk 2013). .

\section{Study design}

Six of the seven studies were parallel-group studies, and one used cluster randomisation (Honkoop 2014). Five were multicentre studies (Calhoun 2012; Hashimoto 2011; Honkoop 2014; Shaw 2007; Syk 2013); the remaining two were a dual-centre study, in Powell 2011, and a single-centre study, in Smith 2005.

Two studies used a three-arm strategy to adjust inhaled corticosteroids (Calhoun 2012; Honkoop 2014). Calhoun et al's strategy arms were based on (i) National Heart, Lung, and Blood Institute guidelines (physician assessment-based adjustment (PABA) group), (ii) measurement of exhaled nitric oxide (biomarkerbased adjustment (BBA)), or (iii) occurrence of symptoms prompting rescue use of albuterol (symptom-based adjustment $(\mathrm{SBA})$ ). As the PABA strategy utilised a national guideline, we used this group as the control group and the BBA strategy as the intervention group.

Honkoop et al's study also had three arms, which targeted (i) partially controlled asthma (PCa), (ii) controlled asthma (Ca), or 
(iii) FeNO-driven controlled asthma (FCa) (Honkoop 2014). The controlled asthma strategy was used as the control group.

Despite Hashimoto et al's study fitting the inclusion criteria (Hashimoto 2011), we could not include some of their data in the meta-analysis as the adjustments were based on the dose of oral corticosteroids. Hashimoto 2011 used an internetbased management tool comprised of (i) an electronic diary that included FeNO measurement, (ii) treatment decision support for the participants, and (iii) monitoring support by the study nurse.

Of the seven studies, two were double blind (Calhoun 2012; Powell 2011), two were single blind (Shaw 2007; Smith 2005), and three had no blinding (Hashimoto 2011; Honkoop 2014; Syk 2013).

The study duration varied, ranging from 4 months to 12 months (Table 1). Each study defined exacerbations differently (Table 1 ).

\section{Control group}

Four of the seven studies utilised existing asthma guidelines to adjust treatment in the control group (Calhoun 2012; Hashimoto 2011; Shaw 2007; Smith 2005). Two studies used the Asthma Control Test (Honkoop 2014; Powell 2011). One study utilised a combination of patient-reported symptoms, bronchodilator use, physical examination, and spirometry results (Syk 2013) (Table 1).

\section{FeNO strategy}

The intervention arm in all seven studies, although primarily based on FeNO level, differed in the cutoff for FeNO for change in therapy. Syk 2013 was the only study utilising different cutoffs for men and women. No studies took into account the presence of atopy.

The FeNO cutoffs used for the studies are presented in Table 1.

\section{Participants}

The seven included studies used different inclusion criteria to recruit participants. While all participants had to have asthma, how the diagnosis was defined varied across the studies. Two studies defined asthma as per current guidelines (Hashimoto 2011; Honkoop 2014). Six studies defined asthma as the current use of asthma medications (Hashimoto 2011; Honkoop 2014; Powell 2011; Shaw 2007; Smith 2005; Syk 2013). Calhoun 2012 and Syk 2013 based their definition of asthma on physician diagnosis and positive airway hyper-responsiveness.

\section{Outcomes}

Four studies used asthma exacerbations or time-to-treatment failure as their primary outcome (Calhoun 2012; Powell 2011; Shaw 2007; Smith 2005). Each study defined exacerbations differently; see Table 1. Hashimoto 2011 used Asthma Control Questionnaire and quality of life as their primary outcome. Honkoop 2014 used quality-adjusted life years as their primary outcome. One study used the change in Juniper Mini Asthma Quality of Life Questionnaire as their primary outcome (Syk 2013).

Secondary outcomes also varied among the studies. Four studies used spirometry (Calhoun 2012; Hashimoto 2011; Honkoop 2014; Syk 2013). Two studies included asthma exacerbations (Hashimoto 2011; Honkoop 2014). In four studies asthma-related quality of life was a secondary outcome (Calhoun 2012; Honkoop 2014; Powell 2011; Syk 2013), and three studies used dose of inhaled corticosteroids (Shaw 2007; Smith 2005; Syk 2013).

\section{Excluded studies}

We excluded 24 studies; the reasons for the exclusion are presented in the Characteristics of excluded studies table. The most common reasons for exclusion were: not a randomised controlled trial $(n=$ $7)$, treatment not adjusted to FeNO $(n=6)$, and participants were not adults $(n=9)$. We found a further study in abstract form only (Duong-Quy 2015). We contacted the study author of Duong-Quy 2015 in June 2016 and confirmed that the paper was in preparation, therefore we judged this study as ongoing, to be included in the next update.

\section{Risk of bias in included studies}

Full details of 'Risk of bias' judgements can be found in the 'Risk of bias' section at the end of each Characteristics of included studies table; a 'Risk of bias' summary can be found in Figure 2. Overall, the methodological quality of the included studies was high. 
Figure 2. Risk of bias summary: review authors' judgements about each risk of bias item for each included study.

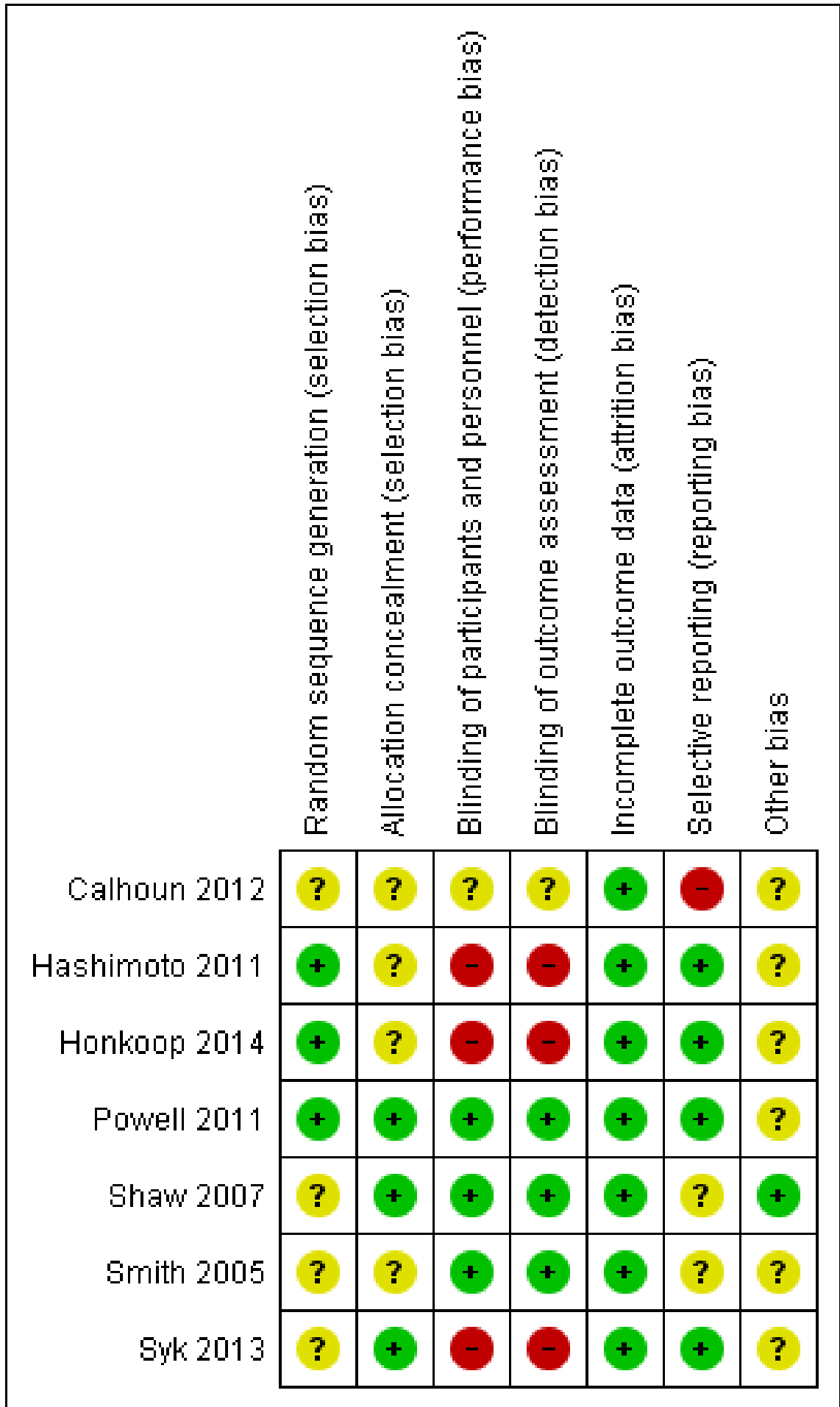

\section{Allocation}

Generation of the randomisation sequence was described in three studies (Hashimoto 2011; Powell 2011; Syk 2013), and unclear in four studies (Calhoun 2012; Honkoop 2014; Shaw 2007; Smith 2005). We determined the method of allocation concealment to be adequate in three studies (Powell 2011; Shaw 2007; Syk 2013), and unclear in three (Calhoun 2012; Honkoop 2014; Smith 2005).
However, we assessed one study as at high risk of bias for allocation concealment (Hashimoto 2011).

\section{Blinding}

We deemed the risk associated with participant blinding to be low when the study authors reported blinding of the assessors. These were: "a third party provided advice on treatment decisions" and 
"both arms of the study received the same follow-up including measurements and tests".

We considered risk of detection bias due to inadequate blinding of outcome assessors to be high in three studies (Hashimoto 2011; Honkoop 2014; Syk 2013), and unclear in one (Calhoun 2012), as there was not enough information in the published protocol and article. We judged three studies as having a low risk of bias (Powell 2011; Shaw 2007; Smith 2005).

\section{Incomplete outcome data}

We assessed all studies as having a low risk of attrition bias.

\section{Selective reporting}

We considered three studies to have a low risk of reporting bias (Hashimoto 2011; Honkoop 2014; Powell 2011), with all outcome measures being reported. We judged three studies as unclear as there was not enough information provided in the published article (Shaw 2007; Smith 2005; Syk 2013). We judged Calhoun 2012 as high risk as some of the secondary outcomes reported were not correctly labelled or an incorrect analysis method was utilised.

\section{Other potential sources of bias}

Another source of bias was the success of obtaining FeNO levels at each visit according to current guidelines. Six studies did not report the success of obtaining FeNO at each time point (Calhoun 2012; Hashimoto 2011; Honkoop 2014; Powell 2011; Smith 2005; Syk 2013). One study reported that they successfully obtained FeNO at each visit (Shaw 2007).

\section{Effects of interventions}

See: Summary of findings for the main comparison Tailoring asthma treatment using FeNO versus clinical symptoms

See Summary of findings for the main comparison for the main comparisons.

\section{Primary outcome: Asthma exacerbations}

Four of the included studies used asthma exacerbations as their primary outcome (Calhoun 2012; Powell 2011; Shaw 2007; Smith 2005). See Table 1 for the definitions of exacerbations used. Five studies reported a reduction in asthma exacerbations in the intervention arm compared to the controls (treatment was based primarily on clinical symptoms) (Honkoop 2014; Powell 2011; Shaw 2007; Smith 2005; Syk 2013). For the various types of exacerbations, data from the studies were combined into the meta-analysis, as described below.

\subsection{Number of participants who had one or more exacerbations over the study period}

Analysis 1.1

Hashimoto 2011 did not report on this outcome in the paper and provided their data through correspondence (31 in FeNO group and 24 in control group had one or more exacerbation). Combined data from five studies showed that the number of participants experiencing an exacerbation was significantly lower $(P=0.003)$ in the FeNO group compared to the control (clinical symptom) group over the study period; pooled odds ratio (OR) (fixed-effect model) was OR 0.60 (95\% confidence interval $(\mathrm{Cl}) 0.43$ to 0.84 ; participants
$=1005$; studies $=5)$. There was no heterogeneity among the studies; $1^{2}=13 \%$. In the control group 149 out of 529 participants had at least one exacerbation over the study period, compared to 116 out of 539 for the FeNO group. The number needed to treat to benefit (NNTB) over 52 weeks was 12 ( $95 \% \mathrm{Cl} 8$ to 32 ).

\subsection{Number of exacerbations per 52 weeks (exacerbation rate)}

Analysis 1.2

Combined data from five studies for this outcome also showed a significant $(P=0.0001)$ reduction favouring the FeNO group; rate ratio (RR) 0.59 ( $95 \% \mathrm{Cl} 0.45$ to 0.77 ; participants $=842$; studies $=5)$. There was no statistical no heterogeneity among the studies. The rate of exacerbation over the 52 weeks in the control group ranged from 0.23 to 0.9 .

\subsection{Severe exacerbations requiring oral corticosteroids}

\section{Analysis 1.3}

Three studies reporting the use of oral corticosteroids could be combined in a meta-analysis, showing no significant difference between the groups (OR 0.86, $95 \% \mathrm{Cl} 0.50$ to 1.48 ; participants $=495$; studies $\left.=3 ; 1^{2}=0 \%\right)$.

\subsection{Severe exacerbations requiring hospitalisation}

Analysis 1.4

Five studies reported hospitalisations due to worsening of asthma symptoms, but no participants were hospitalised in two studies (Shaw 2007; Syk 2013). We did not include Hashimoto 2011 and Honkoop 2014 in the meta-analysis because they were cluster randomised trials or due to the complexity of the intervention used. In the Hashimoto 2011 study a total of nine people were hospitalised (four in FeNO group and five in the control strategy). The meta-analysis showed no significant difference between the groups $(\mathrm{OR} 0.14,95 \% \mathrm{Cl} 0.01$ to 2.67; participants $=488$; studies $=$ $\left.3 ; 1^{2}=0 \%\right)$.

\section{Secondary outcomes}

\section{$1.5 \mathrm{FEV}_{1} \%$ predicted at final visit}

Analysis 1.5

None of the included studies reported lung function, but we obtained further data from the authors of four studies. There was no significant difference between groups (mean difference (MD) 0.11 , $95 \% \mathrm{Cl}-1.15$ to 1.37 ; participants $=802$; studies $=4$ ). Shaw et al reported that "there was no difference in FEV1 between the groups over the duration of the study", but no details were provided (Shaw 2007).

\subsection{FeNO level (ppb) at final visit}

Analysis 1.6

Five studies reported FeNO at final visit. The forest plot showed no significant difference between the groups (standardised mean difference (SMD) $-0.00,95 \% \mathrm{Cl}-0.16$ to 0.15 ; participants $=668$; studies $=5 ; 12=0 \%)$. A random-effects analysis did not change the results (SMD $-0.00,95 \% \mathrm{Cl}-0.16$ to 0.15 ; participants $=668$; studies $=5)$. 


\subsection{Symptom score: Asthma Control Test}

Analysis 1.7

Four studies reported Asthma Control Test results. Meta-analysis showed no significant difference between groups (MD $-0.08,95 \% \mathrm{Cl}$ -0.18 to 0.01 ; participants $=707$; studies $=4 ;\left.\right|^{2}=0 \%$ )

\subsection{Symptom score: Asthma-related quality of life}

Analysis 1.8

Combined data from only two studies found no significant difference between groups for the Asthma Quality of Life Questionnaire (AQLQ) (MD 0.00, 95\% Cl -0.10 to 0.10; participants = 621 ; studies $=2$ ). Data from Hashimoto et al could not be included in the meta-analysis, but reported that asthma-related quality of life did not differ between the study groups (Hashimoto 2011).

\subsection{Inhaled corticosteroids dose at final visit (budesonide equivalent in mcg/day)}

Analysis 1.9

There was no significant difference between the groups' inhaled corticosteroid (ICS) dose at final visit in the meta-analysis of four studies (MD $-17.01,95 \% \mathrm{Cl}-101.75$ to 67.72 ; participants $=582$; studies $\left.=4 ; I^{2}=82 \%\right)$. There was significant statistical heterogeneity for this outcome, likely due to the large doses of steroids used in one study (Smith 2005). Using random-effects, the difference between groups remained non-significant (MD $-147.15 \mathrm{mcg} /$ day, $95 \% \mathrm{Cl}-380.85$ to 86.56$)$.

\section{Subgroup analysis and investigation of heterogeneity}

\section{Basis for adjustment of ICS in the control group (guideline- driven monitoring versus non-guideline driven)}

\section{Analysis 1.10 and Analysis 1.11}

Four of the included studies utilised guideline-driven monitoring for the control group (Calhoun 2012; Hashimoto 2011; Shaw 2007; Smith 2005). In this subgroup, for the primary outcome of exacerbation, the significant difference between groups was no longer present. There were no differences between groups for the number of participants who had one or more exacerbations (OR $0.87,95 \% \mathrm{Cl} 0.47$ to 1.61 ). The exacerbation rate was also not significantly different between groups ( $R R 0.76,95 \% \mathrm{Cl} 0.48$ to 1.19 ; $P=0.23)$.

In the other three studies (Honkoop 2014; Powell 2011; Syk 2013), the adjustments were not guideline based. The meta-analysis of this subgroup significantly favoured the FeNO arm compared to the control arm; the number of participants who had one or more exacerbation (OR $0.51,95 \% \mathrm{Cl} 0.34$ to 0.76 ) and exacerbation rate between groups (RR $0.51,95 \% \mathrm{Cl} 0.37$ to 0.71 ).

When testing the subgroup differences, there was no difference between the two subgroups for either outcome; Analysis 1.10 reports no subgroup difference $(P=0.16)$. Likewise, Analysis 1.11 reports no difference $(P=0.17)$.

\section{Use of spirometry or peak flow as an adjunctive monitoring tool for adjustment of medications (versus non-use of spirometry or peak flow)}

Two studies utilised spirometry when adjusting medications in the control group (Honkoop 2014; Syk 2013), however as spirometry was not the sole measurement for adjusting the medications, this subgroup analysis could not be done. As per Table 1, Honkoop 2014 utilised the Asthma Control Test, 7-item version, which includes spirometry, and Syk 2013 used patient-reported symptoms, shortacting beta-agonist use, physical review in addition to spirometry.

\section{Baseline ICS dose at commencement of intervention (low- medium (< $800 \mathrm{mcg} /$ day budesonide equivalent) versus high dose ( $800 \mathrm{mcg} /$ day or more budesonide equivalent))}

In four studies (Calhoun 2012; Hashimoto 2011; Shaw 2007; Syk 2013), the median ICS dose at baseline was less than $800 \mathrm{mcg} /$ day budesonide equivalent. However, none of the studies analysed their data based on baseline ICS dose, hence this subgroup analysis could not be done.

\section{FeNO cutoffs for adjustment of medications ( $\leq 20$ ppb versus $>$ $20 \mathrm{ppb})$}

Five studies adjusted medications if FeNO levels were less than or equal to $20 \mathrm{ppb}$, as described in Table 1 (Hashimoto 2011; Powell 2011; Shaw 2007; Smith 2005; Syk 2013). When considering this in the subgroup analysis, the results were similar to the main analyses.

For the primary outcomes of exacerbation, the FeNO group continued to have fewer exacerbations. By removing Honkoop 2014, who adjusted medications when FeNO was greater than 20 $\mathrm{ppb}$, from the first outcome, the number of participants who had more than one exacerbation over the study period, the difference remained statistically different $(\mathrm{OR} 0.59,95 \% \mathrm{Cl} 0.41$ to $0.85 ; \mathrm{P}=$ $0.004)$. Likewise, for the second primary outcome of exacerbation rate, by removing Calhoun 2012 the FeNO group was favoured (RR $0.57,95 \% \mathrm{Cl} 0.43$ to 0.75 ).

\section{FeNO cutoffs, based on presence of atopy}

None of the included studies considered atopy in their algorithm for FeNO levels, therefore it was not possible to explore atopy through subgroup analysis.

\section{Sensitivity analyses}

1. Excluding studies with a high risk of bias based on the 'Risk of bias' assessment

Three of the included studies did not use blinding (Hashimoto 2011; Honkoop 2014; Syk 2013). However, removing the data from these studies did not alter the results of the primary outcome (exacerbations) found in the main analyses; the number of participants who had one or more exacerbations over the study period (OR $0.63,95 \% \mathrm{Cl} 0.41$ to 0.96 ; participants $=432$; studies $=3$ ) and exacerbation rate $(\mathrm{RR} 0.61,95 \% \mathrm{Cl} 0.45$ to 0.82 ; participants $=$ 661 ; studies $=4)$.

\section{Variation in the inclusion criteria}

One study involving pregnant women only reported that not all included adults were receiving ICS at recruitment (Powell 2011); only $43.1 \%$ of control group and $41.1 \%$ of FeNO group were 
receiving ICS at baseline. Removing this study had little impact on the effect estimate, but resulted in reduced precision for number of participants with one or more exacerbations (OR $0.67,95 \% \mathrm{Cl}$ 0.44 to $1.01 ; \mathrm{P}=0.06$; participants $=785$; studies $=4$ ). The group differences for exacerbation rate remained significantly different between groups, favouring the FeNO group, but again with reduced precision (RR 0.66, 95\% Cl 0.47 to 0.93 ; $\mathrm{P}=0.02$; participants $=622$; studies $=4)$.

\section{Differences in the medications used in the intervention and comparison group}

No studies adjusted medications for only one arm, therefore we did not undertake this planned sensitivity analysis.

\section{Analysis used random-effects model}

Using random-effects did not change the significant group differences for the primary outcomes, that is results favoured the FeNO arm; the number of participants who had one or more exacerbations over the study period (OR $0.61,95 \% \mathrm{Cl} 0.42$ to 0.87 ; participants $=1005$; studies $=5)$ and exacerbation rate (RR 0.59, $95 \%$ $\mathrm{Cl} 0.45$ to 0.77 ; participants $=842$; studies $=5$ ).

\section{Analysis by 'strategy received'}

Four studies used hierarchy management protocols that were based solely on the use of steroids for each step (that is without consideration for using montelukast or long-acting beta-agonist or both at any point) (Calhoun 2012; Hashimoto 2011; Shaw 2007; Smith 2005). Removing these studies from the analyses did not alter the significant group differences found in the main analyses, which favoured the FeNO arm; the number of participants who had one or more exacerbation over the study period (OR $0.51,95 \% \mathrm{Cl} 0.34$ to 0.76 ; participants $=793$; studies $=3$ ) and exacerbation rate (RR 0.51, $95 \% \mathrm{Cl} 0.37$ to 0.71 ; participants $=401$; studies $=2$ ).

\section{DISCUSSION}

\section{Summary of main results}

We found seven RCTs involving 1700 participants (1546 completed) that could be included in this review. The studies varied in the FeNO levels and algorithms used. The duration of the studies also differed, ranging from 4 to 12 months.

All studies reported our review's primary outcome (exacerbation), but the definition varied among the studies. We could combine data from a maximum of five studies for the meta-analysis of the different exacerbation types. The number of people having one or more asthma exacerbation was significantly lower in the FeNO group compared to the control group (OR $0.60,95 \% \mathrm{Cl} 0.43$ to 0.84). The NNTB over 52 weeks was 12 (95\% Cl 8 to 32). Those in the FeNO group were also significantly more likely to have a lower exacerbation rate than the controls (RR $0.59,95 \% \mathrm{Cl} 0.45$ to 0.77 ). However, we did not find a difference between the groups for exacerbations requiring hospitalisation (OR $0.14,95 \% \mathrm{Cl} 0.01$ to 2.67 ) or rescue oral corticosteroids (OR $0.86,95 \% \mathrm{Cl} 0.50$ to 1.48 ); only three studies contributed to the latter outcome.

There was also no significant difference between groups for any of the secondary outcomes ( $\mathrm{FEV}_{1}$, FeNO levels, symptoms scores, or ICS doses at final visit).
In the subgroup analyses, when the analyses were restricted to the studies that utilised guidelines as the control group, the main analyses for the primary outcome of exacerbations were altered, with no difference seen between the FeNO and control groups for the number of participants who had one or more exacerbation (OR $0.87,95 \% \mathrm{Cl} 0.47$ to 1.61 ) or exacerbation rate (RR $0.76,95 \% \mathrm{Cl}$ 0.48 to 1.19$)$. There were no subgroup differences for either primary outcome.

In the sensitivity analyses, the only changes from the primary outcome analyses were seen when removing one study that included pregnant participants not receiving ICS at the beginning of the study (Powell 2011). The pooled effect size was similar, but there was a loss of precision for both number of participants with one or more exacerbation (OR $0.67,95 \% \mathrm{Cl} 0.44$ to $1.01 ; \mathrm{P}=0.06$ ) and exacerbation rate ( $R R 0.66,95 \% \mathrm{Cl} 0.47$ to $0.93 ; \mathrm{P}=0.02$ ).

\section{Overall completeness and applicability of evidence}

This review included seven studies, but the meta-analyses could only include data from between two and five studies for the various outcomes, including our review's primary outcome. The total number of participants for the various outcomes ranged from 488 (outcome: severe exacerbations requiring hospitalisation) to 1005 (outcome: number of participants who had one or more exacerbations over the study period). Thus, although we contacted authors of the studies, the completeness of the review was limited by availability of data.

Despite two of the primary outcomes ('number of participants who had one or more exacerbations over the study period' and 'exacerbation rate') favouring the FeNO arm, there were no significant group differences for severe exacerbations (requiring oral corticosteroids or hospitalisation) or for symptom scores and end-of-study FEV ${ }_{1}$, FeNO, or ICS doses. In the subgroup analyses, when considering only the studies that utilised guidelines for the control group (Calhoun 2012; Hashimoto 2011; Shaw 2007; Smith 2005), for the primary outcomes of exacerbations we found no difference between the FeNO and control groups. However, undertaking the sub-analysis resulted in a loss of power. In contrast, when analyses were restricted to the studies that did not utilise guidelines (Honkoop 2014; Powell 2011; Syk 2013), the difference in exacerbation rates between the FeNO and control groups remained significant.

Hashimoto 2011 included participants with severe asthma who had received long courses of oral corticosteroids (daily up to 46 median months) and who were on high doses of ICS. Including this study, which involved the most severe type of patients with asthma, in the meta-analyses would have made some of the outcomes difficult to interpret, as it was designed to taper oral steroids, whereas the other six included studies were adjusting inhaled asthma medications. One study examined pregnant women (Powell 2011); as it is unknown how FeNO levels are affected during pregnancy, extrapolation of this review to pregnancy is limited. Furthermore, less than $50 \%$ of women in this study were on ICS at baseline. As the participants in the rest of the studies were on ICS, results of this review should not be extrapolated to adults with asthma who do not require daily ICS to control their symptoms.

One study used cluster randomisation with three treatment strategies (Honkoop 2014), therefore not all data could be included in the meta-analyses, as the raw data did not allow for the clustering 
and inclusion of this data could have resulted in a unit-of-analysis error.

The study setting also varied among the seven studies, with five studies undertaken in primary care and two hospital-based. All of the studies were undertaken in the last 11 years in affluent countries: two in the Netherlands (Hashimoto 2011; Honkoop 2014), one in Sweden (Syk 2013), one in the US (Calhoun 2012), one in Australia (Powell 2011), one in the UK (Shaw 2007), and one in New Zealand (Smith 2005). Given the absence of data from low- and middle-income countries, the findings of our review have limited applicability in resource-poor settings.

Furthermore, as ethnicity likely influences FeNO levels in otherwise healthy people (ATS FeNO 2005), the FeNO cutoff values used to adjust the medications may be race or ethnicity dependent.

Some of the included studies were over 10 years old, and substantial research has been undertaken and published in the past decade. Recently, Harnan et al conducted a systematic review and economic evaluation for the National Institute for Health and Care Excellence (NICE) to assess the diagnostic accuracy, clinical effectiveness, and cost-effectiveness of three hand-held FeNO analysers (Harnan 2015). The review, which included 27 studies, concluded that FeNO-guided management has the potential to be cost-effective. However, the evidence for using FeNO for diagnosis and management was deemed inconclusive (Harnan 2015).

Lastly, asthma is a heterogenous condition, and there is increasing appreciation of non-eosonophilic asthma and overlap syndromes (with COPD) (Karampitsakos 2016). As FeNO levels reflect lower airway eosinophilia in steroid-naive people, the data from this review is unlikely to be applicable to those with non-eosonophilic asthma, smokers, overlap syndromes, and/or exacerbations that are non-eosonophilic asthma.

\section{Quality of the evidence}

We summarised the evidence for the three main outcomes related to exacerbations and ICS dose in the 'Summary of findings' table. Overall, we judged the quality of evidence to be very low to moderate. Three studies were non-blinded (Hashimoto 2011; Honkoop 2014; Syk 2013), which reduced our confidence in the accuracy in these reported studies. The sensitivity analysis without these studies indicated that the results from the blinded studies still showed a reduction in the risk of exacerbations, but in view of the different FeNO cutoffs used between the studies for adjustment of maintenance treatment and the shortage of evidence from trials that compared FeNO to guideline-adjusted treatment, we downgraded the evidence in GRADE, as displayed in Summary of findings for the main comparison.

The quality of evidence for the outcome of ICS dose at final visit was very low. This could be due to variation in the ICS doses, with one study having particularly high doses (360 to $1282 \mathrm{mcg}$ in the control groups and 423 to $740 \mathrm{mcg}$ in the FeNO groups). There was substantial statistical heterogeneity in the analysis $\left(1^{2}=82 \%\right.$; $P=0.0007)$. We therefore downgraded this outcome by one for heterogeneity and one for imprecision.

\section{Potential biases in the review process}

We are unaware of any biases in the review process. We used a comprehensive search strategy and adhered to the protocol. Two review authors (HP, KK) independently assessed the risk of bias. We contacted the corresponding authors of all the studies for raw data to include in the meta-analysis. KK and the review editor (Christopher Cates) independently checked the data extraction, 'Risk of bias' assessment, and downgrading decisions for the 'Summary of findings' table in order to minimise the risk of bias in the review process.

The inclusion of Hashimoto 2011 in the meta-analyses would have introduced bias, as the strategy used was a complex intervention of which FeNO was only one part, however this study contributed only to the meta-analysis of the final FeNO level (Analysis 1.6).

\section{Agreements and disagreements with other studies or reviews}

This review updated a previous Cochrane review that included paediatric and adult studies (Petsky 2009). We decided to separate the reviews based on population ages and the increased clinical trials on the subject. The original review included two adult studies and four paediatric studies involving a total of 1010 participants who completed the trials (Petsky 2009). This adult-only review includes seven studies involving a total 1546 participants who completed the trials. A separate paediatric review includes nine studies with a total of 1390 children who completed the trials. The paediatric Cochrane review has yet to be completed to compare the results with this Cochrane review involving adults (Petsky 2015b).

The results of Petsky 2009 differed from this current review, showing no difference between the groups for the primary outcome of exacerbations. Both adult papers included in the original review, Shaw 2007 and Smith 2005, reported that their FeNO group experienced fewer exacerbations than the clinical-symptoms group, but the differences were not significant. When the data were combined, the number of participants who had one or more exacerbations over the study period did not differ $(P=0.76)$ between the FeNO group and the clinical-symptoms group (pooled OR $0.85,95 \% \mathrm{Cl} 0.30$ to 2.43 ). However, the combined data from five studies in this review showed that the number of participants experiencing an exacerbation was significantly lower $(P=0.003)$ in the FeNO group compared to the control (clinical-symptoms) group over the study period; pooled OR (fixed-effect model) was 0.60 (95\% $\mathrm{Cl} 0.43$ to 0.84) (Honkoop 2014; Powell 2011; Shaw 2007; Smith 2005; Syk 2013). There was no heterogeneity among the studies (12 $=13 \%)$. In the control group, 149 out of 529 participants had at least one exacerbation over the study period, compared to 116 out of 539 for the FeNO group. The NNTB over 52 weeks was 12 (95\% Cl 8 to 32) (Figure 3). 
Figure 3. In the control group, 25 people out of 100 had exacerbations over 52 weeks, compared to 17 (95\% Cl 13 to 22 ) out of 100 for the active treatment group. NNTB 12 (95\% Cl 8 to 32).

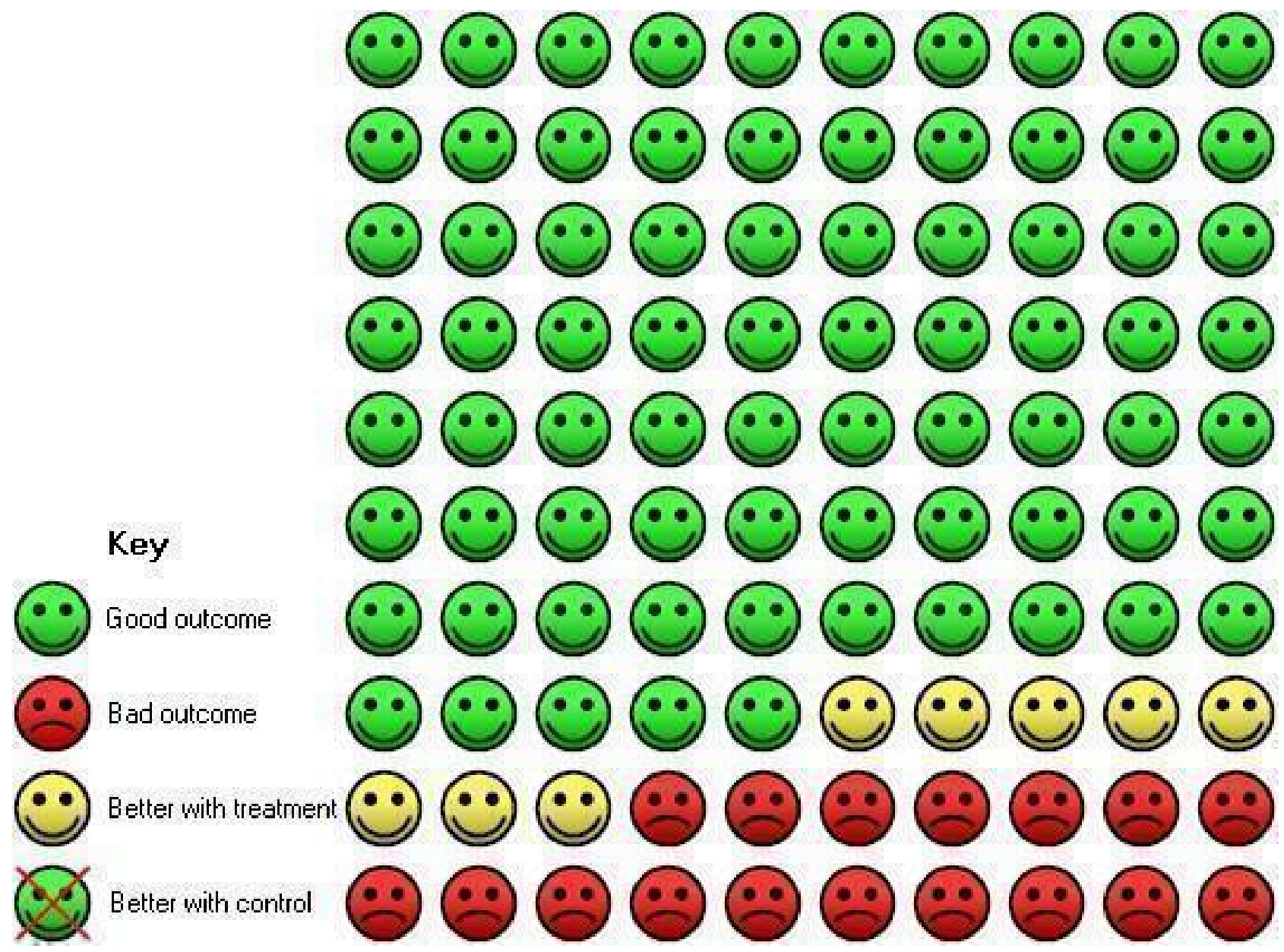

ICS dose at final visit favoured the FeNO group in the original Cochrane review (MD $-450.03,95 \% \mathrm{Cl}-676.73$ to $-222.34 ; \mathrm{P}<0.0001$ ) (Petsky 2009). The original review combined the data from 98 participants allocated to the FeNO group. In this current review, the combined data for the outcome of ICS dose at final visit included 296 participants and did not favour either group (MD -17.01, 95\% Cl -101.75 to $67.72 ; \mathrm{P}=0.69$ ).

Essat et al published a systematic review on the utility of FeNO for adjusting asthma medications. The Essat 2016 review included only six of the seven studies included in our Cochrane review. The Essat 2016 paper also acknowledged the heterogeneity among the studies and called for further research. In contrast to our findings on the lack of difference between groups for ICS dose at final visit, the Essat 2016 paper found a significant difference between groups. In this Cochrane review, we used a standardised dose (that is budesonide equivalent), but this conversion was not undertaken in Essat 2016.

The Essat 2016 paper found a decrease in the FeNO group for the outcome of 'all exacerbation and treatment failure rates' with the inclusion of three studies (RR $0.53,95 \% \mathrm{Cl} 0.46$ to 0.61 , P $<0.00001)$; our Cochrane review found similar results for this outcome involving five studies (Analysis 1.1).
Another published systematic review, Lu 2015, was based on children only and hence not comparable to our review, which evaluated adults only. Likewise, Gomersal et al reported a systematic review in children but did not undertake a meta-analysis comparing FeNO-guided management with any other monitoring strategy for children with asthma (Gomersal 2016). We will consider both these papers, Essat 2016 and Gomersal 2016, in the Cochrane review on children (Petsky 2015b).

No guidelines currently recommend the routine use of FeNO in monitoring asthma. However, NICE guidelines are currently focusing on the impact and feasibility of implementing FeNO in a diagnosis algorithm.

\section{AUTHORS' CONCLUSIONS}

\section{Implications for practice}

This review has demonstrated that tailoring asthma medications based on exhaled nitric oxide (FeNO) levels significantly reduce exacerbation numbers and rates, but found no significant difference between groups in hospitalisations or rescue oral corticosteroids courses. There were also no significant differences between groups for any of our secondary outcomes: $\mathrm{FEV}_{1}$, ICS dosage, FeNO levels, or symptoms scores. Additionally, none of the studies reported a cost analysis. The use of FeNO to help 
guide therapy in adults with asthma cannot thus be universally advocated, but may be useful in some subpopulations. As the main benefit shown in the studies in this review was a reduction in asthma exacerbations, the intervention may be most useful in adults who have frequent exacerbations.

\section{Implications for research}

Further double-blind, parallel-group RCTs are required. Studies should also take into account various cutoffs for FeNO levels and other significant influences on FeNO levels such as atopy, sex, and ethnicity. A one-size-fits-all approach in relation to FeNO levels may not be providing a clear picture. The effects of tailoring asthma medications based on different levels of severity should also be examined. Cost analyses and adverse events of inhaled and oral corticosteroids would also provide additional important information.

\section{ACKNOWLEDGEMEN T S}

We thank Elizabeth Stovold for conducting the relevant searches.

We also thank the study authors who provided further data for inclusion into the meta-analyses: Heather Powell, Simone Hashimoto, Dominic Shaw, Persijn Honkoop, and Jörgen Syk.

We are very grateful to Dr Christopher Cates, the Editor for this review, who commented critically on the review and assisted in the data analyses.

The Background and Methods section of this review are based on a standard template used by Cochrane Airways Group. 


\section{R E F E R E N C E S}

\section{References to studies included in this review}

\section{Calhoun 2012 \{published data only\}}

Calhoun W, Ameredes B, King T, Icitovic N, Bleecker E, Castro M, et al. Comparison of physician-, biomarker-, and symptombased strategies for adjustment of inhaled corticosteroid therapy in adults with asthma. JAMA 2012;308(10):987-97.

\section{Hashimoto 2011 \{published data only\}}

Hashimoto S, Ten Brinke A, Roldaan A, van Veen I, Moller G, Sont J, et al. Internet-based tapering of oral corticosteroids in severe asthma: a pragmatic randomised controlled trial. Thorax 2011;66:514-20. [DOI: 10.1136/thx.2010.153411]

\section{Honkoop 2014 \{published data only\}}

Honkoop P, Lijmans R, Termeer E, Snoeck-Stroband J, van den Hout W, Bakker M, et al. Symptom- and fraction of exhaled nitric oxide-driven strategies for asthma control: A clusterrandomized trial in primary care. Journal of Allergy and Clinical Immunology 2015;135:682-8. [DOI: 10.1016/j.jaci.2014.07.016]

\section{Powell 2011 \{published and unpublished data\}}

Burgess L, McCaffery K, Powell H, Murphy VE, Gibson PG, Turner RM. The influence of asthma control on psychosocial outcomes for pregnant women with asthma. Journal of Asthma 2015 Aug 24 [Epub ahead of print]. [DOI: 10.3109/02770903.2015.103883]

Murphy V, Powell H, Gibson P. Exacerbations following step down and step up inhaled corticosteroid therapy in the managing asthma in pregnancy (MAP) study. Respirology 2015;20:54

Murphy VE, Powell H, Gibson PG. Exacerbations of asthma following changes in inhaled corticosteroids (ICS) and long acting beta agonist (LABA) therapy in the managing asthma in pregnancy (MAP) study. Journal of Paediatrics and Child Health 2015;51:64. [Conference abstract]

* Powell H, Murphy V, Taylor DR, Hensley M, McCaffery K, Giles W, et al. Management of asthma in pregnancy guided by measurement of fraction of exhaled nitric oxide: a double-blind, randomised controlled trial. The Lancet 2011;378:983-90. [DOI: 10.1016/S0140-6736(11)60971-9]

\section{Shaw 2007 \{published data only\}}

Shaw D, Berry M, Thomas M, Green R, Brightling C, Wardlaw A, et al. The use of exhaled nitric oxide to guide asthma management - A randomized controlled trial. American Journal of Respiratory and Critical Care Medicine 2007;176:231-7. [DOI: 10.1164/rccm.200610-14270C]

\section{Smith 2005 \{published data only\}}

Smith AD, Cowan J, Brassett KP, Herbison GP, Taylor DR. Use of exhaled nitric oxide measurements to guide treatment in chronic asthma. The New England Journal of Medicine 2005:352:2163-73.
Syk 2013 \{published data only\}

Syk J, Malinovschi, Johansson G, Unden A, Andreasson A, Lekander M, et al. Anti-inflammatory treatment of atopic asthma guided by exhaled nitric oxide: A randomized, controlled trial. Journal of Allergy and Clinical Immunology Practice 2013;1:639-48. [DOI: 10.1016/j.jaip.2013.07.013]

\section{References to studies excluded from this review}

\section{Anderson 2012 \{published and unpublished data\}}

Anderson WJ, Short PM, Williamson PA, Lipworth BJ. Inhaled corticosteroid dose response using domiciliary exhaled nitric oxide in persistent asthma: the FeNOtype trial. Chest 2012;142:1553-61. [DOI: 10.1378/chest.12-1310]

\section{de Jongste 2009 \{published data only\}}

de Jongste JC, Carraro S, Hop WC, CHARISM Study Group, Baraldi E. Daily telemonitoring of exhaled nitric oxide and symptoms in the treatment of childhood asthma. American Journal of Respiratory and Critical Care Medicine 2008;179:93-7. [DOI: 10.1164/rccm.200807-10100C]

\section{Fritsch 2006 \{published data only\}}

Fritsch M, Uxa S, Horak F, Putschoegl B, Dehlink E, Szepfalusi Z, et al. Exhaled nitric oxide in the management of childhood asthma: A prospective 6-months study. Pediatric Pulmonology 2006;41:855-62. [DOI: 10.1002/ppul.20455]

\section{Gelb 2006 \{published data only\}}

Gelb A, Flynn Taylor C, Shinar CM, Gutierrez C, Zamel N. Role of spirometry and exhaled nitric oxide to predict exacerbations in treated asthmatics. Chest 2006;129(6):1492-9. [DOI: 10.1378/ chest.129.6.1492]

\section{Griese 2000 \{published data only\}}

Griese M, Koch M, Latzin P, Beck J. Asthma severity, recommended changes of inhaled therapy and exhaled nitric oxide in children: a prospective, blinded trial. European Journal of Medical Research 2000;5(8):334-40. [PUBMED: PMID 10958766

\section{Gruchalla 2009 \{published data only\}}

Gruchalla RS, Sampson HA, Matsui E, David G, Gergen PJ, Calatroni A, et al. Asthma morbidity among inner-city adolescents receiving guidelines-based therapy: role of predictors in the setting of high adherence. Journal of Allergy and Clinical Immunology 2009;124:213-21. [DOI: 10.1016/ j.jaci2009.05.036]

\section{Jatakanon 1999 \{published data only\}}

Jatakanon A, Kharitonov S, Lim S, Barnes PJ. Effect of differing doses of inhaled budesonide on markers of airway inflammation in patients with mild asthma. Thorax 1999;54(2):108-14. [DOI: 10.1136/thx.54.2.108]

\section{Jones 2001 \{published data only\}}

Jones SL, Kittelson J, Cowan JO, Flannery EM, Hancox RJ, McLachlan CR, et al. The predictive value of exhaled nitric 
oxide measurements in assessing changes in asthma control. American Journal of Respiratory and Critical Care Medicine 2001;164(5):738-43. [DOI: 10.1164/ajrccm.164.5.2012125]

\section{Jones 2002 \{published data only\}}

Jones SL, Herbison P, Cowan JO, Flannery EM, Hancox RJ, McLachlan CR, et al. Exhaled NO and assessment of antiinflammatory effects of inhaled steroids: Dose-response relationship. European Respiratory Journal 2002;20(3):601-8. [DOI: 10.1183/09031936.02.00285302]

\section{Kharitonov 1996 \{published data only\}}

Kharitonov SA, Yates DH, Chung KF, Barnes PJ. Changes in the dose of inhaled steroid affect exhaled nitric oxide in asthmatic patients. European Respiratory Journal 1996;9(2):196-201. [PUBMED: 8777950]

\section{Kharitonov 2002 \{published data only\}}

Kharitonov SA, Konnelly LE, Corradi M, Montuschi P, Barnes PJ. Dose-dependent onset and cessation of action of inhaled budesonide on exhaled nitric oxide and symptoms in mild asthma. Thorax 2002;57(1):889-96. [DOI: 10.1136/ thorax.57.10.889]

\section{Lim 1998 \{published data only\}}

Lim S, Jatakanon A, Uasuf C, Chung KF, Barnes PJ. Clinical utility of exhaled nitric oxide as a marker of disease activity in asthma. American Journal of Respiratory and Critical Care Medicine 1998;157(3 Suppl):A611.

\section{Malerba 2008 \{published data only\}}

Malerba M, Ragnoli B, Radaeli A, Tantucci C. Usefulness of exhaled nitric oxide and sputum eosinophils in the long-term control of eosinophilic asthma. Chest 2008;134:733-9. [DOI: 10.1378/chest.08-0763]

\section{Peirsman 2014 \{published data only\}}

Peirsman EJ, Carvelli TJ, Hage PY, Hanssens LS, Pattyn L, Raes MM, et al. Exhaled nitric oxide in childhood allergic asthma management: A randomised controlled trial. Pediatric Pulmonology 2014;49:624-31. [DOI: 10.1002/ppul.22873]

\section{Petsky 2015a \{published data only\}}

Petsky HL, Li AM, Au CT, Kynaston JA, Turner C, Chang AB. Management based on exhaled nitric oxide levels adjusted for atopy reduces asthma exacerbations in children: A dual centre randomized controlled trial. Pediatric Pulmonology 2015;50:535-43. [DOI: 10.1002/ppul.23064]

\section{Pijnenburg 2005 \{published data only\}}

Pijnenburg M, Bakker E, Hop W, de Jongste J. Titrating steroids on exhaled nitric oxide in children with asthma. American Journal of Respiratory and Critical Care Medicine 2005;172(7):831-6. [DOI: 10.1164/rccm.200503-4580C]

\section{Pike 2013 \{published data only\}}

Pike K, Selby A, Price S, Warner J, Connett G, Legg J, et al. Exhaled nitric oxide monitoring does not reduce exacerbation frequency or inhaled corticosteroid dose in paediatric asthma: a randomised controlled trial. The Clinical Respiratory Journal 2013;7(2):204-13. [DOI: 10.1111/j.1752-699X.2012.00306.x]

\section{Powell 2015 \{published data only\}}

Powell H, Murphy VE, Hensley MJ, Giles W, Clifton VL, Gibson PG. Rhinitis in pregnant women with asthma is associated with poorer asthma control and quality of life. Journal of Asthma 2015 Sep 12 [Epub ahead of print]. [DOI: 10.3109/02770903.2015.1054403]

\section{Szefler 2008 \{published data only\}}

Szefler SJ, Mitchell H, Sorkness CA, Gergen PJ, O'Connor GT, Morgan WJ, et al. Management of asthma based on exhaled nitric oxide in addition to guideline-based treatment for innercity adolescents and young adults: a randomised controlled trial. The Lancet 2008;372(9643):1065-72. [DOI: 10.1016/ S0140-6736(08)61448-8]

\section{Verini 2010 \{published data only\}}

Verini M, Consilvio NP, Di Pillo S, Cingolani A, Spagnuolo C, Rapino D, et al. FeNO as a marker of airways inflammation: The possible implications in childhood asthma management. Journal of Allergy 2010;2010:7. [DOI: 10.1155/2010/691425]

\section{Voorend-van Bergen 2013 \{published data only\}}

Bergen SV, Beerthuizen T, van den Hout W, Vaessen-Verberne A, Brackel H, Landstra A, et al. Cost-effectiveness of FeNO- and web-based monitoring in pediatric asthma management. European Respiratory Journal. 2015; Vol. 46.

Voorend-van Bergen S, Vaessen-Verberne A, Landstra A, Brackel $H$, van Den Breg N, de Jongste J, et al. FeNO and webbased monitoring in paediatric asthma management: the BATMAN study. European Respiratory Society Annual Congress. 2013; Vol. 42:629s.

* Voorend-van Bergen S, Vaessen-Verberne AA, Brackel HJ, Landstra AM, van den Berg NJ, Hop WC. Monitoring strategies in children with asthma: a randomised controlled trial. Thorax 2015;70:543-50. [DOI: 10.1136/thoraxjnl-2014-206161]

\section{Zacharasiewicz 2005 \{published data only\}}

Zacharasiewicz A, Wilson N, Lex C, Erin EM, Li AM, Hansel T, et al. Clinical use of noninvasive measurements of airway inflammation in steroid reduction in children. American Journal of Respiratory and Critical Care Medicine 2005;171(10):1077-82. [DOI: 10.1164/rccm.200409-12420C]

\section{References to ongoing studies}

Duong-Quy 2015 \{published data only\}

Duong-Quy S, Hua-Huy T, Doan-Quynh N, Nguyen-Quoc B, LeQuang K, Tran-Thanh D, et al. A study of exhaled NO (FeNO) measurement used to determine asthma control, dose of inhaled corticosteroid and cost in a developing country. European Respiratory Journal. 2015; Vol. 46.

\section{Additional references}

ATS FeNO 2005

American Thoracic Society. ATS/ERS recommendations for standardized procedures for the online and offline measurement of FeNO. American Journal of Critical Care 
and Respiratory Medicine 2005;171:912-30. [DOI: 10.1164/

rccm.200406-710ST]

\section{BTS/SIGN 2014}

British Guideline on the Management of Asthma: A national clinical guideline. http://brit-thoracic.org.uk/ (accessed 16 December 2014).

\section{Cates 2008 [Computer program]}

Dr Christopher Cates. Visual Rx. Online NNT Calculator. Dr Christopher Cates, 2008.

\section{Douwes 2002}

Douwes J, Gibson P, Pekkanen J, Pearce N. Non-eosinophilic asthma: importance and possible mechanisms. Thorax 2002;53:91-5.

\section{Dupont 1998}

Dupont LJ, Rochette F, Demedts MG, Verleden GM. Exhaled nitric oxide correlates with airway hyperresponsiveness in steroid-naive patients with mild asthma. American Journal of Respiratory and Critical Care Medicine 1998;157:894-8.

\section{Essat 2016}

Essat M, Harnan S, Gomersall T, Tappenden P, Wong R, Pavord I, et al. Fractional exhaled nitric oxide for the management of asthma in adults: a systematic review. European Respiratory Journal 2016;47:751-68. [DOI: 10.1183/13993003.01882-2015]

\section{GINA 2014}

From the Global Strategy for Asthma Management and Prevention, Global Initiative for Asthma (GINA) 2014. http:// www.ginasthma.org/local/uploads/files/GINA_Report_2014_ Aug12.pdf (accessed 31 October 2014).

\section{Gomersal 2016}

Gomersal T, Harnan S, Essat M, Tappenden P, Wong R, Lawson R, et al. A systematic review of fractional exhaled nitric oxide in the routine management of childhood asthma. Pediatric Pulmonology 2016;51:316-28. [DOI: 10.1002/ppul.23371]

\section{GRADEpro [Computer program]}

Jan Brozek, Andrew Oxman, Holger Schunemann. GRADEpro Version 3.2. Jan Brozek, Andrew Oxman, Holger Schunemann, 2008.

\section{Harnan 2015}

Harnan SE, Tappenden P, Essat M, Gomersall T, Minton J, Wong $R$, et al. Measurement of exhaled nitric oxide concentration in asthma: a systematic review and economic evaluation of NIOX MINO, NIOX VERO and NObreath. Health Technology Assessment 2015;19:1-368. [DOI: 10.3310/hta19820]

\section{Higgins 2011}

Higgins JPT, Green S (editors). Cochrane Handbook for Systematic Reviews of Interventions Version 1.0 [updated March 2011]. The Cochrane Collaboration, 2011. Available from www.cochrane-handbook.org.

\section{Jatakanon 1998}

Jatakanon A, Lim S, Kharitonov SA, Chung KF, Barnes PJ. Correlation between exhaled nitric oxide, sputum eosinophils and methacholine responsiveness. Thorax 1998;53:91-5.

\section{Karampitsakos 2016}

Karampitsakos T, Gourgoulianis KI. Asthma-COPD Overlap Syndrome (ACOS): Single disease entity or not? Could exhaled nitric oxide be a useful biomarker for the differentiation of ACOS, asthma and COPD?. Medical Hypotheses 2016;91:20-3. [DOI: 10.1016/j.mehy.2016.04.008]

\section{Lu 2015}

Lu M, Wu B, Che D, Qiao R, Gu H. FeNO and asthma treatment in children. Medicine 2015;94:e347. [DOI: 10.1097/ MD.0000000000000347]

\section{Muller 2005}

Muller KC, Jorres RA, Magnussen H, Holz O. Comparison of exhaled nitric oxide analysers. Respiratory Medicine 2005;99:631-7.

\section{National Asthma Council 2014}

National Asthma Council Australia, Melbourne, 2014. Australian Asthma Handbook, Version 1.0. http:// www.nationalasthma.org.au/handbook (accessed 31 October 2014).

\section{Petsky 2015b}

Petsky HL, Kew KM, Kynaston JA, Turner C, Chang AB. Exhaled nitric oxide levels to guide treatment for children with asthma. Cochrane Database of Systematic Reviews 2015, Issue 1. [DOI: 10.1002/14651858.CD011439]

\section{RevMan 2014 [Computer program]}

The Nordic Cochrane Centre, The Cochrane Collaboration. Review Manager (RevMan). Version 5.3. Copenhagen: The Nordic Cochrane Centre, The Cochrane Collaboration, 2014.

\section{Wardlaw 2000}

Wardlaw AJ, Brightling C, Green R, Woltmann G, Pavord I. Eosinophils in asthma and other allergic diseases. British Medical Bulletin 2000;56:985-1003.

\section{Weiss 2001}

Weiss KB, Sullivan SD. The health economics of asthma and rhinitis. I. Assessing the economic impact. Journal of Allergy and Clinical Immunology 2001;107:3-8.

\section{References to other published versions of this review Petsky 2009}

Petsky HL, Cates CJ, Li A, Kynaston JA, Turner C, Chang AB. Tailored interventions based on exhaled nitric oxide versus clinical symptoms for asthma in children and adults. Cochrane Database of Systematic Reviews 2009, Issue 4. [DOI: 10.1002/14651858.CD006340.pub3]

* Indicates the major publication for the study 


\section{CHARACTERISTICS OF STUDIES}

\section{Characteristics of included studies [ordered by study ID]}

\section{Calhoun 2012}

$\begin{array}{ll}\text { Methods } & \text { Randomised, parallel, 3-group, placebo-controlled, double-blinded multicentred trial comparing } 3 \\ \text { strategies to adjust inhaled corticosteroids in adults with mild to moderate asthma. The } 3 \text { strategies } \\ \text { were: a strategy based on National Heart, Lung, and Blood Institute guidelines (PABA group), measure- } \\ \text { ment of exhaled nitric oxide (BBA), or occurrence of symptoms prompting rescue use of albuterol (SBA } \\ \text { group) }\end{array}$

\begin{tabular}{|c|c|}
\hline Participants & $\begin{array}{l}363 \text { participants were enrolled with } 342 \text { randomised. } \\
\text { PABA group N = 114; mean age } 34 \text { (SD 12), } 42 \text { male, } 72 \text { female. } \\
\text { BBA group N = 115; mean age } 35 \text { (SD 11), } 33 \text { male, } 82 \text { female. } \\
\text { SBA group N = 113; mean age } 36 \text { (SD 12), } 30 \text { male, } 83 \text { female. } \\
\text { Participants were recruited with a concurrent Asthma Clinical Research Network trial, but it was un- } \\
\text { clear as to where study visits occurred. } \\
\text { Inclusion criteria: Physician diagnosis of asthma and either reversible airflow limitation ( } \geq 12 \% \text { im- } \\
\text { provement in } F E V_{1} \text { after } 360 \text { ug albuterol) or airway hyper-responsiveness (provocative concentration } \\
\text { of methacholine }(<8 \mathrm{mg} / \mathrm{mL} \text { ) causing a } 20 \% \text { drop in FEV1) }\end{array}$ \\
\hline
\end{tabular}

Interventions The adults with mild to moderate asthma on inhaled corticosteroids had their medications adjusted using 1 of 3 strategies:

- PABA group: a strategy based on National Heart, Lung, and Blood Institute guidelines

- BBA group: measurement of exhaled nitric oxide

- SBA group: occurrence of symptoms prompting rescue use of albuterol

Outcomes Primary outcome: Time to first treatment failure, a clinically important worsening of asthma

Secondary outcomes: Spirometry, albuterol reversibility, methacholine responsiveness, sputum eosinophils, daytime and nighttime symptom and rescue beta-agonist diaries, ACT, Asthma Symptom Utility Index, and AQLQ.

Notes

The control group used for the analysis was the PABA group, which utilised guidelines.

Funding: The study was conducted with the support of the Institute for Translational Sciences at the University of Texas Medical Branch, supported in part by a Clinical and Translational Science Award from the National Center for Advancing Translational Sciences, National Institutes of Health and by National Institutes of Health Grants awarded by the National Heart, Lung, and Blood Institute. Teva Pharmaceuticals provided the study drug and matching placebo. The National Heart, Lung, and Blood Institute had no role in the design and conduct of the study; in the collection, analysis, and interpretation of the data; or in the preparation, review, or approval of the manuscript

\section{Risk of bias}

\begin{tabular}{lll}
\hline Bias & Authors' judgement & Support for judgement \\
\hline $\begin{array}{l}\text { Random sequence genera- } \\
\text { tion (selection bias) }\end{array}$ & Unclear risk & $\begin{array}{l}\text { No description of how sequence was generated. Protocol from Asthma Clinical } \\
\text { Research Network also had no details of sequence generation }\end{array}$ \\
\hline $\begin{array}{l}\text { Allocation concealment } \\
\text { (selection bias) }\end{array}$ & Unclear risk & $\begin{array}{l}\text { Concealment not described in the publication. Protocol states that "the mod- } \\
\text { ule set up by DCC" will be used }\end{array}$ \\
\hline
\end{tabular}


Calhoun 2012 (Continued)

Blinding of participants Unclear risk Study states multiblinded study and puffers labelled A, B, C. However, it is unand personnel (perforclear if the puffers could be recognised by participants or physicians or both, mance bias)

All outcomes

i.e. whether they identical in appearance

\begin{tabular}{lll}
\hline $\begin{array}{l}\text { Blinding of outcome as- } \\
\text { sessment (detection bias) } \\
\text { All outcomes }\end{array}$ & Unclear risk & As for blinding of participants, this is also unclear \\
\hline $\begin{array}{l}\text { Incomplete outcome data } \\
\text { (attrition bias) } \\
\text { All outcomes }\end{array}$ & Low risk & $\begin{array}{l}\text { Primary outcome was time to treatment failure (asthma exacerbation) and } \\
\text { secondary outcomes reported }\end{array}$ \\
\hline $\begin{array}{l}\text { Selective reporting (re- } \\
\text { porting bias) }\end{array}$ & High risk & $\begin{array}{l}\text { Some secondary outcomes are reported incorrectly, with label not correlating } \\
\text { with the results published }\end{array}$ \\
\hline $\begin{array}{l}\text { Other bias } \\
\text { Unclear risk }\end{array}$ & $\begin{array}{l}\text { Days from school lost was reported, but unsure of age used in the inclusion cri- } \\
\text { teria. The mean ages of the groups ranged from 34.2 to 36 years old }\end{array}$ \\
\hline
\end{tabular}

Hashimoto 2011

$\begin{array}{ll}\text { Methods } & \text { Randomised, parallel, multicentred trial comparing } 2 \text { oral corticosteroid tapering strategies. The } 2 \\ \text { strategies were: internet-based monitoring system (internet strategy) or conventional treatment based } \\ \text { on GINA guidelines (conventional strategy) }\end{array}$

Participants

150 people were assessed for eligibility, 95 participants were randomised. 89 participants were included in the ITT analysis.

Internet strategy $\mathrm{N}=51$, mean age 48.5 (SD 12.5), 23 male, 28 female.

Conventional strategy $\mathrm{N}=38$, mean age 52.4 (SD 11.7), 18 male, 20 female.

All participants were outpatients from 2 tertiary academic hospitals or 4 large community hospitals in the Netherlands.

Inclusion criteria: Aged 18 to 75 years, diagnosis of severe refractory asthma as per ATS minor and major criteria. Their asthma needed to be uncontrolled and being assessed by a respiratory physician for at least 1 year, currently on oral corticosteroids, high doses of ICS and long-acting bronchodilators.

Exclusion criteria: Smokers or non-smokers with history of > 15 pack-years. No internet or mobile telephone

Interventions

Monthly visits for 6 months with usual respiratory physician. Daily, participants registered their dose of oral corticosteroids, lung function, and FeNO before taking their medications. Weekly, they completed the ACT. AQLQ completed at baseline and 3 monthly after this. Participants also registered every asthma event such as hospital visit, deterioration in symptoms, and antibiotic use.

Internet strategy: Had steroid dose adjusted based on the 3 components: electronic diary, in-built algorithm (which includes FeNO levels), and monitoring support, e.g. coaching by study nurse and monitoring data, which was entered.

Conventional strategy: Their oral steroids down-titrated by the respiratory physician at their monthly visit. The physicians treated the participants based on GINA guidelines for patients with severe asthma

Outcomes

Primary outcomes: Cumulative sparing of oral corticosteroids (actual cumulative dose minus the expected cumulative dose), ACT, and AQLQ. 
Hashimoto 2011 (Continued)

Secondary outcomes: Global satisfaction scale, $\mathrm{FEV}_{1}$, number of exacerbations, and days of hospitalisation

Notes

No information provided on how successful the daily monitoring was and how compliant participants were with daily tasks.

Funding: This study was funded by the Netherlands Organisation for Health Research and Development (ZonMw). Equipment for the analysis of nitric oxide was provided by Aerocrine AB. The funding sources had no role in the study design, data collection, analysis or interpretation, or in the decision to submit this article for publication

\title{
Risk of bias
}

\begin{tabular}{|c|c|c|}
\hline Bias & Authors' judgement & Support for judgement \\
\hline $\begin{array}{l}\text { Random sequence genera- } \\
\text { tion (selection bias) }\end{array}$ & Low risk & Computer generated \\
\hline $\begin{array}{l}\text { Allocation concealment } \\
\text { (selection bias) }\end{array}$ & Unclear risk & 'Unblinded after randomisation'; implies it was concealed, but no details \\
\hline $\begin{array}{l}\text { Blinding of participants } \\
\text { and personnel (perfor- } \\
\text { mance bias) } \\
\text { All outcomes }\end{array}$ & High risk & Non blinded \\
\hline $\begin{array}{l}\text { Blinding of outcome as- } \\
\text { sessment (detection bias) } \\
\text { All outcomes }\end{array}$ & High risk & Non blinded therefore high risk of detection bias \\
\hline $\begin{array}{l}\text { Incomplete outcome data } \\
\text { (attrition bias) } \\
\text { All outcomes }\end{array}$ & Low risk & All outcome data reported \\
\hline $\begin{array}{l}\text { Selective reporting (re- } \\
\text { porting bias) }\end{array}$ & Low risk & All data reported \\
\hline Other bias & Unclear risk & $\begin{array}{l}\text { Nil information provided in the published article regarding success in obtain- } \\
\text { ing FeNO on each visit }\end{array}$ \\
\hline
\end{tabular}

\section{Honkoop 2014}

\section{Methods}

\begin{abstract}
3-armed cluster randomised trial comparing 3 strategies aiming at either partially controlled asthma (PCa), controlled asthma (Ca), or FeNO-driven controlled asthma ( $\mathrm{FCa}$ ). Cluster randomisation was performed at the general-practice level to prevent intervention contamination within practices. Participants visited the practice every 3 months for 1 year and had their current medication assessed, asthma control assessed using ACT, lung function and FeNO performed in the FCa group only.
\end{abstract}

There was no blinding.

There were 31 dropouts prior to any interventions: 12 in PCa group, 6 in Ca group, and 13 in FCa group. In addition to these dropouts, 5 participants attended only once
Participants
3662 adults were assessed for eligibility, 647 of which were randomised.
PCa group N = 219; mean age 39 (SD 9), 150 female, 69 males.
Ca group $\mathrm{N}=203$; mean age 40 (SD 10), 134 female, 69 males. 
FCa group N = 189; mean age 39 (SD 9), 137 female, 62 males.

All participants were attending general practices in the regions of Amsterdam, Leiden, and Nijmegen in the Netherlands.

Inclusion criteria: Aged 18 to 50 years, doctor-diagnosed asthma according to Dutch national guidelines, prescribed ICS for at least 3 months in the previous 12 months, and asthma being managed in primary care.

Exclusion criteria: Significant comorbidity (at the doctor's discretion), inability to understand Dutch, and a prescription for oral corticosteroids in the previous month

Interventions

Outcomes
At each visit the participant's asthma control was assessed based on the ACT score as controlled ( $\leq$ 0.75 ), partly controlled ( 0.75 to 1.5$)$, or uncontrolled (>1.5). Additionally, participants in the FCa group were categorised based on FeNO levels as: low/absence of airway inflammation $\leq 25 \mathrm{ppb}$, intermediate 26 to $50 \mathrm{ppb}$, and high/presence of airway inflammation $>50 \mathrm{ppb}$. Treatment decisions were based on an algorithm for each strategy, with an online decision support tool for implementing the strategy

Primary outcome: societal costs per quality-adjusted life year (QALY) gained.

Secondary outcomes: asthma control, asthma-related quality of life, number of days with asthma-related limitations of activity, medication adherence, severe exacerbation rate, lung function, FeNO value, and total medication use

Notes Control group used for analysis in this review was the controlled asthma (Ca) group.

Funding: This study was supported by the Netherlands Organisation for Health Research and Development and by the Netherlands Asthma Foundation. Aerocrine (Solna, Sweden) provided 20 of a total of 40 fraction of exhaled nitric oxide meters for free

\section{Risk of bias}

\begin{tabular}{|c|c|c|}
\hline Bias & Authors' judgement & Support for judgement \\
\hline $\begin{array}{l}\text { Random sequence genera- } \\
\text { tion (selection bias) }\end{array}$ & Low risk & $\begin{array}{l}\text { An independent researcher randomly allocated the general practice to } 1 \text { of the } \\
3 \text { treatment strategies. Stratified according to region, urbanisation grade (rural } \\
\text { versus urban), and practice nurse's level of experience with asthma manage- } \\
\text { ment ( }>1 \text { year or }<1 \text { year) }\end{array}$ \\
\hline $\begin{array}{l}\text { Allocation concealment } \\
\text { (selection bias) }\end{array}$ & Unclear risk & $\begin{array}{l}\text { Authors stated that "allocation was applied to both the cluster and participant } \\
\text { levels". However, it is unclear in the published article how this was achieved }\end{array}$ \\
\hline $\begin{array}{l}\text { Blinding of participants } \\
\text { and personnel (perfor- } \\
\text { mance bias) } \\
\text { All outcomes }\end{array}$ & High risk & No blinding \\
\hline $\begin{array}{l}\text { Blinding of outcome as- } \\
\text { sessment (detection bias) } \\
\text { All outcomes }\end{array}$ & High risk & No blinding \\
\hline $\begin{array}{l}\text { Incomplete outcome data } \\
\text { (attrition bias) } \\
\text { All outcomes }\end{array}$ & Low risk & All outcome data reported and analysed as ITT \\
\hline $\begin{array}{l}\text { Selective reporting (re- } \\
\text { porting bias) }\end{array}$ & Low risk & All data presented and analysed as ITT \\
\hline Other bias & Unclear risk & $\begin{array}{l}\text { Nil information provided in the published article regarding success in obtain- } \\
\text { ing FeNO on each visit }\end{array}$ \\
\hline
\end{tabular}


Powell 2011

Methods

Randomised, parallel, double-blind controlled trial of FeNO-guided therapy in 2 antenatal clinics. Expectant mothers were randomised to a FeNO-guided algorithm for adjusting asthma therapy or a clinical-guideline algorithm. The randomisation was stratified by maintenance budesonide dose $(<800 \mathrm{ug}$ per day or $>800$ ug per day).

The participant, research assistant, and investigators were blinded to the randomisation group.

There were 17 dropouts, 11 in the FeNO group and 6 in the control group.

The women were reviewed monthly until delivery

Participants 242 women were recruited, of which 220 were randomised.
FeNO group N = 111; mean age 28 (range 27 to 29$)$.
Control group N = 109; mean age 29 (range 28 to 30).
Attending antenatal clinics at 2 hospitals in New South Wales, Australia.
Inclusion: Non-smoking pregnant women (aged $>18$ years) with asthma using inhaled therapy and at-
tending the clinic. They were recruited at between 12 and 20 weeks' gestation

Interventions The women were seen monthly until they delivered.

Clinical-symptom data, ACT score, present treatment, FeNO, and $\mathrm{FEV}_{1}$ were collected at each visit. ACT score, FeNO levels, and current treatment were sent to the algorithm keeper via facsimile for treatment recommendations.

FeNO group: Sequential process, first FeNO concentrations used to adjust ICS dose, and second ACT score used to adjust the LABA dose.

Clinical group: Based on asthma control using Juniper ACT with cutoff points defined as: well-controlled asthma (ACT < 0.75), partially controlled asthma ( 0.75 to 1.50$)$, and uncontrolled asthma $(>1.5)$

Outcomes Primary outcome: Total number of asthma exacerbations (i.e. moderate and severe).

Secondary outcomes: QoL, asthma treatment, and fetal outcomes

Notes

Funding: This study was funded by the National Health and Medical Research Council of Australia

\section{Risk of bias}

\begin{tabular}{|c|c|c|}
\hline Bias & Authors' judgement & Support for judgement \\
\hline $\begin{array}{l}\text { Random sequence genera- } \\
\text { tion (selection bias) }\end{array}$ & Low risk & $\begin{array}{l}\text { Randomisation was completed in blocks of } 4 \text { with an equal treatment alloca- } \\
\text { tion ratio }\end{array}$ \\
\hline $\begin{array}{l}\text { Allocation concealment } \\
\text { (selection bias) }\end{array}$ & Low risk & $\begin{array}{l}\text { A statistician used computer-generated random number list for randomisation } \\
\text { and stratified by maintenance budesonide dose at visit two ( < } 800 \text { ug per day } \\
\text { or } \geq 800 \text { ug per day) }\end{array}$ \\
\hline $\begin{array}{l}\text { Blinding of participants } \\
\text { and personnel (perfor- } \\
\text { mance bias) } \\
\text { All outcomes }\end{array}$ & Low risk & $\begin{array}{l}\text { Double blind. The use of an algorithm keeper was not masked but was not di- } \\
\text { rectly involved in the care or assessment of the participant }\end{array}$ \\
\hline $\begin{array}{l}\text { Blinding of outcome as- } \\
\text { sessment (detection bias) } \\
\text { All outcomes }\end{array}$ & Low risk & $\begin{array}{l}\text { Assessment of asthma control was made by investigators who were blinded to } \\
\text { the participant's randomisation group. The algorithm keeper received the ACT } \\
\text { score, FeNO level and current treatment via facsimile and applied the appro- }\end{array}$ \\
\hline
\end{tabular}


Powell 2011 (Continued)

priate algorithm and sent the treatment recommendation to the research assistant who informed the participant

\begin{tabular}{|c|c|c|}
\hline $\begin{array}{l}\text { Incomplete outcome data } \\
\text { (attrition bias) } \\
\text { All outcomes }\end{array}$ & Low risk & All outcome data presented \\
\hline $\begin{array}{l}\text { Selective reporting (re- } \\
\text { porting bias) }\end{array}$ & Low risk & All data presented \\
\hline
\end{tabular}

Shaw 2007

Methods

Randomised, single-blind controlled trial comparing exacerbation frequency and corticosteroid dosage in people whose asthma management was based on measurements of FeNO to a control group where management was based on the British Thoracic Society and Scottish Intercollegiate Guidelines Network treatment guidelines. Stratified by baseline sputum eosinophil count, baseline rescue steroid course in last year.

The participants were blinded to which group they were randomised to. At completion, the participants were asked to record which randomisation group they thought they had been assigned to.

There were 15 dropouts, 6 in FeNO group and 9 in control group.

The study ran for 12 months, and the participants were assessed 10 times

Participants

900 adults were contacted from general-practice registers, of which 118 were randomised.

FeNO group $\mathrm{N}=58$; median age 50 (range 20 to 75), 27 males, 31 females.

Control group $\mathrm{N}=60$; median age 52 (range 24 to 81 ), 27 males, 33 females.

Attending a general practice in Leicester, UK.

Inclusion: > 18 years old, diagnosis of asthma and at least 1 prescription for anti-asthma medication in the past 12 months.

Exclusion: Current smokers, past smoking history of > 10 pack-years, or physician determines that they are poorly compliant

Interventions Participants were seen at baseline, 2 weeks, month: 1, 2, 3, 4, 6, 8, 10, and 12 .

$\mathrm{FEV}_{1}$, FeNO, and Juniper asthma control score (JACS) were undertaken at each visit. Methacholine challenge for sputum induction was undertaken at initial visit, 6 months, and at completion of 12 months.

In control group: Treatment was doubled if JACS $>1.57$, and treatment halved if JACS $<1.57$ for 2 consecutive months.

In FeNO group: When FeNO > 26 ppb, ICS was increased. If $<16$ ppb, or $<26$ ppb on 2 separate occasions, treatment was decreased

Outcomes Primary outcome: Number of exacerbations.

Secondary outcome: Total ICS dose

Notes

Funding: This study was supported by a grant from Asthma UK 
Shaw 2007 (Continued)

Risk of bias

\begin{tabular}{|c|c|c|}
\hline Bias & Authors' judgement & Support for judgement \\
\hline $\begin{array}{l}\text { Random sequence genera- } \\
\text { tion (selection bias) }\end{array}$ & Unclear risk & Insufficient information provided in published article \\
\hline $\begin{array}{l}\text { Allocation concealment } \\
\text { (selection bias) }\end{array}$ & Low risk & $\begin{array}{l}\text { Randomisation was done by an independent individual using minimisation } \\
\text { method, stratified by baseline sputum eosinophil count, FeNO and rescue } \\
\text { steroid courses in the last year }\end{array}$ \\
\hline $\begin{array}{l}\text { Blinding of participants } \\
\text { and personnel (perfor- } \\
\text { mance bias) } \\
\text { All outcomes }\end{array}$ & Low risk & $\begin{array}{l}\text { Single blind. Participants were assessed at completion of study regarding the } \\
\text { group they thought they were assigned to, } 49 \% \text { were unsure of which group } \\
\text { they were assigned. } 33 \% \text { correctly identified their group, and } 18 \% \text { incorrectly } \\
\text { identified their group }\end{array}$ \\
\hline $\begin{array}{l}\text { Blinding of outcome as- } \\
\text { sessment (detection bias) } \\
\text { All outcomes }\end{array}$ & Low risk & $\begin{array}{l}\text { Assessment of asthma control was made by investigators who were blinded to } \\
\text { the participant's randomisation group. A separate unblinded physician com- } \\
\text { municated to the patient the correct treatment decision }\end{array}$ \\
\hline $\begin{array}{l}\text { Incomplete outcome data } \\
\text { (attrition bias) } \\
\text { All outcomes }\end{array}$ & Low risk & No missing outcome data \\
\hline $\begin{array}{l}\text { Selective reporting (re- } \\
\text { porting bias) }\end{array}$ & Unclear risk & Insufficient information \\
\hline Other bias & Low risk & Measurement of FeNO was successful on every occasion \\
\hline
\end{tabular}

Smith 2005

Methods Randomised, placebo-controlled, single-blind study. This was a 2-phase study, with phase 1 varying in duration ( 3 to 12 months), where the dose of inhaled fluticasone was titrated down in a stepwise manner until the optimal dose was deemed to have been achieved. During phase 2 (12 months), optimal dose from phase 1 was continued, and therapy was stepped up if asthma control was lost.

Participants were blinded to which group they were assigned to.

In phase 1 there were 16 dropouts, 13 during run-in and 3 during follow-up. Phase 2 had 5 dropouts during the 12 months

Participants 97 participants were randomised from 110 participants recruited, mean age of 44.8 years (range 12 to 73) and 41 males, 69 females.

FeNO group $\mathrm{N}=46$

Control group $\mathrm{N}=48$

Inclusion criteria: Inhaled corticosteroids for 6 months with no dose change in previous 6 weeks.

Exclusion criteria: $>4$ courses of oral prednisolone in previous 12 months, admission to hospital in the last 6 months, any intensive care admissions, or cigarette smoking (current or past history of $>10$ packyears)

Interventions $\quad$ Phase 1

Run-in period was for 6 weeks, after 2 weeks fluticasone 750 ug/day was commenced. Visits were every 4 weeks until optimal dose was achieved. 
Smith 2005 (Continued)

FeNO group: Adjustment of dose of ICS was based solely to keep FeNO $<15 \mathrm{ppb}$ at $250 \mathrm{~mL} / \mathrm{sec}$.

Control group: Dose adjustment based on asthma symptoms, nighttime waking, bronchodilator use, variation in PEFR and $\mathrm{FEV}_{1}$.

Phase 2

Visits every 2 months.

Upward adjustments made as per phase 1 but no downward adjustments would be made from optimal dose

\begin{tabular}{ll}
\hline Outcomes & Primary outcome: Frequency of exacerbation. \\
& Secondary outcome: Mean daily dose of ICS \\
\hline Notes & $\begin{array}{l}\text { Funding: This study was funded by the Otago Medical Research Foundation, the Dean's Fund of the } \\
\text { Dunedin School of Medicine, and a grant from the University of Otago. Supplies of fluticasone were pro- } \\
\text { vided by GlaxoSmithKline (New Zealand). Equipment for the analysis of nitric oxide in other studies was } \\
\text { provided by Aerocrine }\end{array}$
\end{tabular}

\section{Risk of bias}

\begin{tabular}{|c|c|c|}
\hline Bias & Authors' judgement & Support for judgement \\
\hline $\begin{array}{l}\text { Random sequence genera- } \\
\text { tion (selection bias) }\end{array}$ & Unclear risk & $\begin{array}{l}\text { Insufficient information of randomisation and sequence generation in pub- } \\
\text { lished article }\end{array}$ \\
\hline $\begin{array}{l}\text { Allocation concealment } \\
\text { (selection bias) }\end{array}$ & Unclear risk & Insufficient information of randomisation in published article \\
\hline $\begin{array}{l}\text { Blinding of participants } \\
\text { and personnel (perfor- } \\
\text { mance bias) } \\
\text { All outcomes }\end{array}$ & Low risk & $\begin{array}{l}\text { Single blind. All treatment orders were verified independently by an investiga- } \\
\text { tor who was blinded to treatment group }\end{array}$ \\
\hline $\begin{array}{l}\text { Blinding of outcome as- } \\
\text { sessment (detection bias) } \\
\text { All outcomes }\end{array}$ & Low risk & $\begin{array}{l}\text { Single blind. All treatment orders were verified independently by an investiga- } \\
\text { tor who was blinded to treatment group }\end{array}$ \\
\hline $\begin{array}{l}\text { Incomplete outcome data } \\
\text { (attrition bias) } \\
\text { All outcomes }\end{array}$ & Low risk & Missing data has been imputed using appropriate methods \\
\hline $\begin{array}{l}\text { Selective reporting (re- } \\
\text { porting bias) }\end{array}$ & Unclear risk & Insufficient information provided in published article \\
\hline Other bias & Unclear risk & $\begin{array}{l}\text { Nil information provided in published article regarding success of measuring } \\
\text { FeNO }\end{array}$ \\
\hline
\end{tabular}

Syk 2013

Multicentred, open-label, parallel RCT comparing a FeNO-guided strategy versus usual care to adjust
anti-inflammatory treatment to improve asthma-related QoL and asthma symptoms whilst reducing
asthma exacerbations in atopic participants with asthma in primary care
asthma exacerbations in atopic participants with asthma in primary care 
Syk 2013 (Continued)

FeNO group $\mathrm{N}=87$, mean age 40.9 (SD 11.8), 48 males, 39 females.

Control group $\mathrm{N}=78$, mean age 41.1 (SD 12.9), 46 males, 32 females.

They attended 1 of 17 primary healthcare centres in 7 different autonomous healthcare regions in Sweden.

Inclusion criteria: aged 18 to 64 years, physician's diagnosis of asthma, prescribed ICS for $>6$ months, confirmed IgE sensitisation to $\geq 1$ major airborne perennial allergen (dog, cat, or mite).

Exclusion criteria: pregnancy or breastfeeding, participation in another study, unstable asthma, smokers, solely on montelukast or in combination with budesonide equivalent dose 0 to $400 \mathrm{mcg}$

Interventions

Participants were seen at enrolment, baseline ( 2 to 4 weeks later), month 2 , month 4 , month 8 , and month 12 (final visit).

FeNO, ACT, and registration of exacerbations were undertaken at each visit. mAQLQ and GQLI were attended at baseline, month 4, and month 12 only.

FeNO group: Treatment was adjusted according to a FeNO algorithm and 6 fixed treatment steps.

Control group: Treatment was adjusted according to usual care including patient-reported symptoms, SABA use, physical examination, and lung functions results.

\begin{tabular}{ll}
\hline Outcomes & Primary outcome: change in mAQLQ score during the study. \\
& $\begin{array}{l}\text { Secondary outcome: changes in ACT score, exacerbation frequency, lung function, generic QoL score, } \\
\text { and overall medication use }\end{array}$ \\
\hline Notes & $\begin{array}{l}\text { Funding: This study was funded by the Stockholm county council (PickUP), Centre for Allergy Research, } \\
\text { Karolinska Institute, and the Research Foundation of the Swedish Asthma and Allergy Association. Sup- } \\
\text { port was also received from Aerocrine AB (NIOX MINO instruments), Phadia AB (ImmunoCAP Rapid), } \\
\text { Meda AB (Buventol Easyhaler), and MSD Sweden (small grant) }\end{array}$
\end{tabular}

\section{Risk of bias}

\begin{tabular}{|c|c|c|}
\hline Bias & Authors' judgement & Support for judgement \\
\hline $\begin{array}{l}\text { Random sequence genera- } \\
\text { tion (selection bias) }\end{array}$ & Unclear risk & $\begin{array}{l}\text { Prepared by the study coordinator outside the primary health care centre. } \\
\text { However, unclear how sequence was generated }\end{array}$ \\
\hline $\begin{array}{l}\text { Allocation concealment } \\
\text { (selection bias) }\end{array}$ & Low risk & Envelopes used in lottery randomisation \\
\hline $\begin{array}{l}\text { Blinding of participants } \\
\text { and personnel (perfor- } \\
\text { mance bias) } \\
\text { All outcomes }\end{array}$ & High risk & $\begin{array}{l}\text { Open label. FeNO analyser screen was covered for control group, therefore } \\
\text { study staff member nor participant knew the result. However, the FeNO } \\
\text { analyser screen was not covered in FeNO group }\end{array}$ \\
\hline $\begin{array}{l}\text { Blinding of outcome as- } \\
\text { sessment (detection bias) } \\
\text { All outcomes }\end{array}$ & High risk & $\begin{array}{l}\text { Regarding FeNO as the FeNO group was not blinded to FeNO results which } \\
\text { could influence their symptom scores }\end{array}$ \\
\hline $\begin{array}{l}\text { Incomplete outcome data } \\
\text { (attrition bias) } \\
\text { All outcomes }\end{array}$ & Low risk & All outcome data reported \\
\hline $\begin{array}{l}\text { Selective reporting (re- } \\
\text { porting bias) }\end{array}$ & Low risk & $\begin{array}{l}\text { The named outcomes were well reported in the paper and the study protocol } \\
\text { was prospectively registered. Additional data were provided by study authors }\end{array}$ \\
\hline
\end{tabular}


Syk 2013 (Continued)

Other bias Unclear risk One of the authors (Alving K) was an employee and stock holder of Aerocrine (manufacturer of FeNO analysers)

ACT: Asthma Control Test

AQLQ: Asthma Quality of Life Questionnaire

ATS: American Thoracic Society

BBA: biomarker-based adjustment

FeNO: fractional exhaled nitric oxide

FEV1: forced expiratory volume in 1 second

GINA: Global Initiative for Asthma

GQLI: Göteborg Quality of Life Instrument

ICS: inhaled corticosteroids

IgE: immunoglobulin E

ITT: intention-to-treat

LABA: long-acting beta-agonist

mAQLQ: mini-Asthma Quality of Life Questionnaire

QoL: quality of life

PABA: physician assessment-based adjustment

PEFR: peak expiratory flow rate

$\mathrm{RCT}$ : randomised controlled trial

SABA: short-acting beta-agonist

SBA: symptom-based adjustment

SD: standard deviation

Characteristics of excluded studies [ordered by study ID]

\begin{tabular}{|c|c|}
\hline Study & Reason for exclusion \\
\hline Anderson 2012 & $\begin{array}{l}\text { Excluded as treatment not adjusted according to FeNO. Randomised, cross-over trial evaluating } \\
\text { the dose response of ICS in people with asthma and elevated FeNO }\end{array}$ \\
\hline de Jongste 2009 & $\begin{array}{l}\text { Excluded as study did not include adults but based instead in paediatric population. Included in } \\
\text { paediatric systematic review by same authors }\end{array}$ \\
\hline Fritsch 2006 & $\begin{array}{l}\text { Excluded as study did not include adults but based instead in paediatric population. Included in } \\
\text { paediatric systematic review by same authors }\end{array}$ \\
\hline Gelb 2006 & $\begin{array}{l}\text { Not a RCT, treatment not based on FeNO. Prospective study to assess FeNO and spirometry to pre- } \\
\text { dict asthma exacerbations }\end{array}$ \\
\hline Griese 2000 & $\begin{array}{l}\text { Not a RCT, treatment not based on FeNO. Prospective study to assess FeNO in comparison to symp- } \\
\text { toms adjusted using clinical symptoms }\end{array}$ \\
\hline Gruchalla 2009 & $\begin{array}{l}\text { Excluded as treatment not adjusted according to FeNO. Same dataset as paediatric included study } \\
\text { (Szefler 2008) }\end{array}$ \\
\hline Jatakanon 1999 & $\begin{array}{l}\text { Excluded as treatment not based on FeNO. Randomised into } 2 \text { double-blind, placebo-controlled } \\
\text { studies ( } 1 \text { parallel study involving } 3 \text { groups receiving either budesonide } 110 \text { ug/day, budesonide } \\
400 \text { ug/day, or placebo; the second was a cross-over randomised study to receive budesonide } 1600 \\
\text { ug or placebo) }\end{array}$ \\
\hline Jones 2001 & $\begin{array}{l}\text { Non-RCT. Observational study to determine if FeNO is useful in diagnosing and predicting loss of } \\
\text { asthma control. Participants had ICS withdrawn until loss of control or for a maximum of } 6 \text { weeks }\end{array}$ \\
\hline Jones 2002 & $\begin{array}{l}\text { Excluded as treatment not based on FeNO. Double-blind, parallel-group, placebo-controlled trial of } \\
50,100,200 \text {, or } 500 \text { ug budesonide per day }\end{array}$ \\
\hline
\end{tabular}




\begin{tabular}{ll}
\hline Study & Reason for exclusion \\
\hline Kharitonov 1996 & $\begin{array}{l}\text { Non-RCT. Observational study of the effect of increasing and then reducing the dose of ICS on } \\
\text { FeNO, lung function, and symptoms in people with asthma }\end{array}$ \\
\hline Kharitonov 2002 & $\begin{array}{l}\text { Excluded as treatment not adjusted according to FeNO. Double-blind, placebo-controlled, paral- } \\
\text { lel-group study of } 100 \text { or } 400 \text { ug budesonide or placebo in participants with mild asthma }\end{array}$ \\
\hline Lim 1998 & $\begin{array}{l}\text { Excluded as treatment not adjusted according to FeNO. Randomised, longitudinal study monitor- } \\
\text { ing the effect of increasing anti-inflammatory medication or to continue unchanged using conven- } \\
\text { tional measures of lung function, symptom scores, medication usage, and peak expiratory flow } \\
\text { rate variability }\end{array}$ \\
\hline
\end{tabular}

Malerba 2008 Excluded as non-randomised. Prospective observational study including 14 participants with asth-
ma who had asthma treatment adjusted based on sputum eosinophil counts and FeNO

\begin{tabular}{|c|c|}
\hline Peirsman 2014 & $\begin{array}{l}\text { Excluded as study did not include adults but based instead in paediatric population. Included in } \\
\text { paediatric systematic review by same authors }\end{array}$ \\
\hline Petsky 2015a & $\begin{array}{l}\text { Excluded as study did not include adults but based instead in paediatric population. Included in } \\
\text { paediatric systematic review by same authors }\end{array}$ \\
\hline Pijnenburg 2005 & $\begin{array}{l}\text { Excluded as study did not include adults but based instead in paediatric population. Included in } \\
\text { paediatric systematic review by same authors }\end{array}$ \\
\hline Pike 2013 & $\begin{array}{l}\text { Excluded as study did not include adults but based instead in paediatric population. Included in } \\
\text { paediatric systematic review by same authors }\end{array}$ \\
\hline Powell 2015 & $\begin{array}{l}\text { Excluded as reporting results regarding rhinitis from participants in an included study (Powell } \\
\text { 2011) }\end{array}$ \\
\hline Szefler 2008 & $\begin{array}{l}\text { Excluded as study did not include adults but based instead in paediatric population. Included in } \\
\text { paediatric systematic review by same authors }\end{array}$ \\
\hline Verini 2010 & $\begin{array}{l}\text { Excluded as study did not include adults but based instead in paediatric population. Included in } \\
\text { paediatric systematic review by same authors }\end{array}$ \\
\hline Voorend-van Bergen 2013 & $\begin{array}{l}\text { Excluded as study did not include adults but based instead in paediatric population. Included in } \\
\text { paediatric systematic review by same authors }\end{array}$ \\
\hline Zacharasiewicz 2005 & $\begin{array}{l}\text { Non-RCT. Prospective and observation study in children using non-invasive measures (FeNO, in- } \\
\text { duced sputum, and exhaled breath condensate) to monitor airway inflammation to result in opti- } \\
\text { mal treatment }\end{array}$ \\
\hline
\end{tabular}

FeNO: fractional exhaled nitric oxide ICS: inhaled corticosteroids $\mathrm{RCT}$ : randomised controlled trial

Characteristics of ongoing studies [ordered by study ID]

Duong-Quy 2015

Trial name or title
Exhaled NO (FeNO) measurement used to determine asthma control, dose of inhaled corticosteroid and cost in a developing country

Methods
People with uncontrolled asthma with FeNO $>25$ ppb were included in this study. They were classified into 3 groups according to the intervention used to determine therapy: 
Duong-Quy 2015 (Continued)

group 1 (Gr1): used GINA guidelines, group 2 (Gr2): used GINA plus FeNO, and group $3(\mathrm{Gr} 3)$ : used only FeNO

\begin{tabular}{ll}
\hline Participants & Unknown \\
\hline Interventions & $\begin{array}{l}\text { Group 1 (Gr1): used GINA guidelines, Group 2 (Gr2): used GINA plus FeNO, and Group 3 (Gr3): used } \\
\text { only FeNO }\end{array}$ \\
\hline Outcomes & ICS dose, exacerbations, cost \\
\hline Starting date & Unknown \\
\hline Contact information & Sy Duong-Quy <sduongquy.jfvp@gmail.com> \\
\hline Notes & $\begin{array}{l}\text { Prof Duong-Quy was contacted January 2016, when he stated that the article will be submitted in } \\
\text { the near future }\end{array}$ \\
\hline
\end{tabular}

FeNO: fractional exhaled nitric oxide GINA: Global Initiative for Asthma ICS: inhaled corticosteroids

\section{DATA AND ANALYSES}

Comparison 1. Asthma treatment tailored on FeNO versus clinical symptoms

\begin{tabular}{|c|c|c|c|c|}
\hline Outcome or subgroup title & No. of studies & $\begin{array}{l}\text { No. of partici- } \\
\text { pants }\end{array}$ & Statistical method & Effect size \\
\hline $\begin{array}{l}1 \text { Number of participants who had } \geq 1 \\
\text { exacerbations over study period }\end{array}$ & 5 & 1005 & Odds Ratio (Fixed, 95\% Cl) & $0.60[0.43,0.84]$ \\
\hline $\begin{array}{l}2 \text { Number of exacerbations per } 52 \\
\text { weeks (exacerbation rates) }\end{array}$ & 5 & 842 & Rate Ratio (Fixed, 95\% Cl) & $0.59[0.45,0.77]$ \\
\hline $\begin{array}{l}3 \text { Severe exacerbations requiring oral } \\
\text { corticosteroids }\end{array}$ & 3 & 495 & $\begin{array}{l}\text { Odds Ratio (M-H, Random, } \\
95 \% \mathrm{Cl})\end{array}$ & $0.86[0.50,1.48]$ \\
\hline $\begin{array}{l}4 \text { Severe exacerbations requiring hos- } \\
\text { pitalisation }\end{array}$ & 3 & 488 & $\begin{array}{l}\text { Odds Ratio (M-H, Fixed, 95\% } \\
\mathrm{Cl})\end{array}$ & $0.14[0.01,2.67]$ \\
\hline $5 \mathrm{FEV}_{1} \%$ pred at final visit & 4 & 802 & $\begin{array}{l}\text { Mean Difference (Fixed, 95\% } \\
\mathrm{Cl} \text { ) }\end{array}$ & $0.11[-1.15,1.37]$ \\
\hline 6 FeNO level at final visit & 5 & 668 & $\begin{array}{l}\text { Std. Mean Difference (IV, } \\
\text { Fixed, } 95 \% \mathrm{CI} \text { ) }\end{array}$ & $-0.00[-0.16,0.15]$ \\
\hline $\begin{array}{l}7 \text { Symptom score as per Asthma Con- } \\
\text { trol Test }\end{array}$ & 4 & 707 & $\begin{array}{l}\text { Mean Difference (IV, Fixed, } \\
95 \% \mathrm{Cl} \text { ) }\end{array}$ & $-0.08[-0.18,0.01]$ \\
\hline 8 Symptom score as per AQLQ & 2 & & $\begin{array}{l}\text { Mean Difference (Fixed, 95\% } \\
\mathrm{CI} \text { ) }\end{array}$ & $0.00[-0.10,0.10]$ \\
\hline $\begin{array}{l}9 \text { ICS dose at final visit (microgram } \\
\text { per day) }\end{array}$ & 4 & 582 & $\begin{array}{l}\text { Mean Difference (IV, Ran- } \\
\text { dom, } 95 \% \mathrm{CI} \text { ) }\end{array}$ & $\begin{array}{l}-147.15[-380.85 \\
86.56]\end{array}$ \\
\hline
\end{tabular}




\begin{tabular}{|c|c|c|c|c|}
\hline Outcome or subgroup title & No. of studies & $\begin{array}{l}\text { No. of partici- } \\
\text { pants }\end{array}$ & Statistical method & Effect size \\
\hline $\begin{array}{l}10 \text { Subgroup (control guideline use): } \\
\text { Number of participants who had } \geq 1 \\
\text { exacerbations over study period }\end{array}$ & 5 & & Odds Ratio (Fixed, 95\% Cl) & $0.60[0.43,0.84]$ \\
\hline 10.1 Guideline control & 2 & & Odds Ratio (Fixed, 95\% Cl) & $0.87[0.47,1.61]$ \\
\hline 10.2 Other control & 3 & & Odds Ratio (Fixed, 95\% Cl) & $0.51[0.34,0.76]$ \\
\hline $\begin{array}{l}11 \text { Subgroup (control guideline use): } \\
\text { Number of exacerbations per } 52 \\
\text { weeks (exacerbation rates) }\end{array}$ & 5 & & Rate Ratio (Fixed, 95\% Cl) & $0.59[0.45,0.77]$ \\
\hline 11.1 Guideline control & 3 & & Rate Ratio (Fixed, 95\% Cl) & $0.76[0.48,1.19]$ \\
\hline 11.2 Other control & 2 & & Rate Ratio (Fixed, 95\% Cl) & $0.51[0.37,0.71]$ \\
\hline
\end{tabular}

\section{Analysis 1.1. Comparison 1 Asthma treatment tailored on FeNO versus clinical symptoms, Outcome 1 Number of participants who had $\geq 1$ exacerbations over study period.}

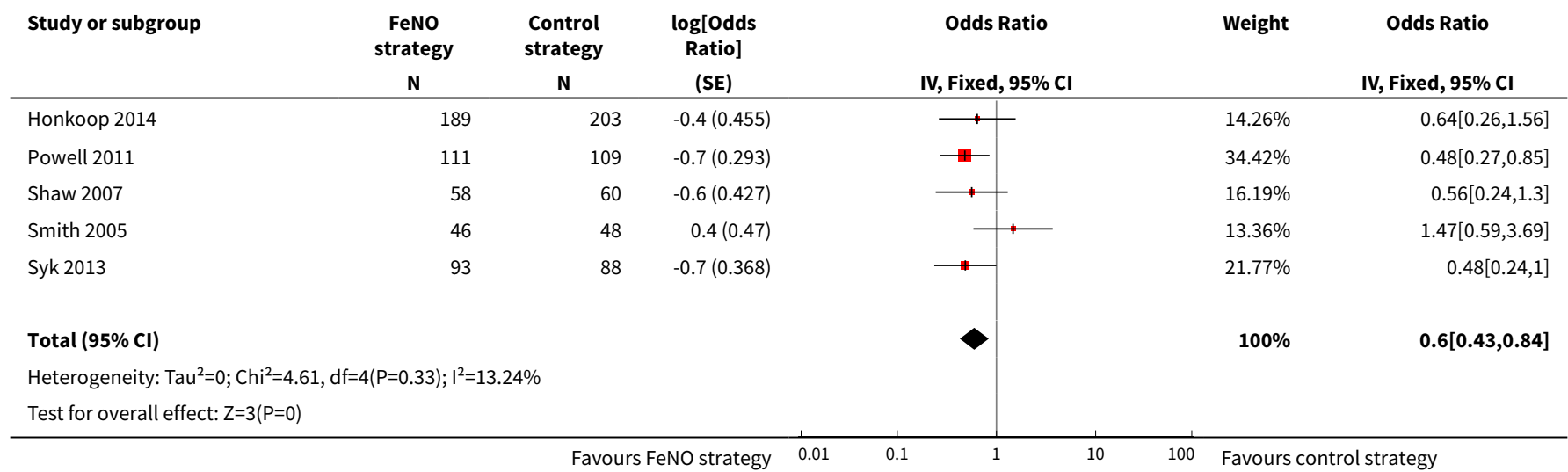

Analysis 1.2. Comparison 1 Asthma treatment tailored on FeNO versus clinical symptoms, Outcome 2 Number of exacerbations per 52 weeks (exacerbation rates).

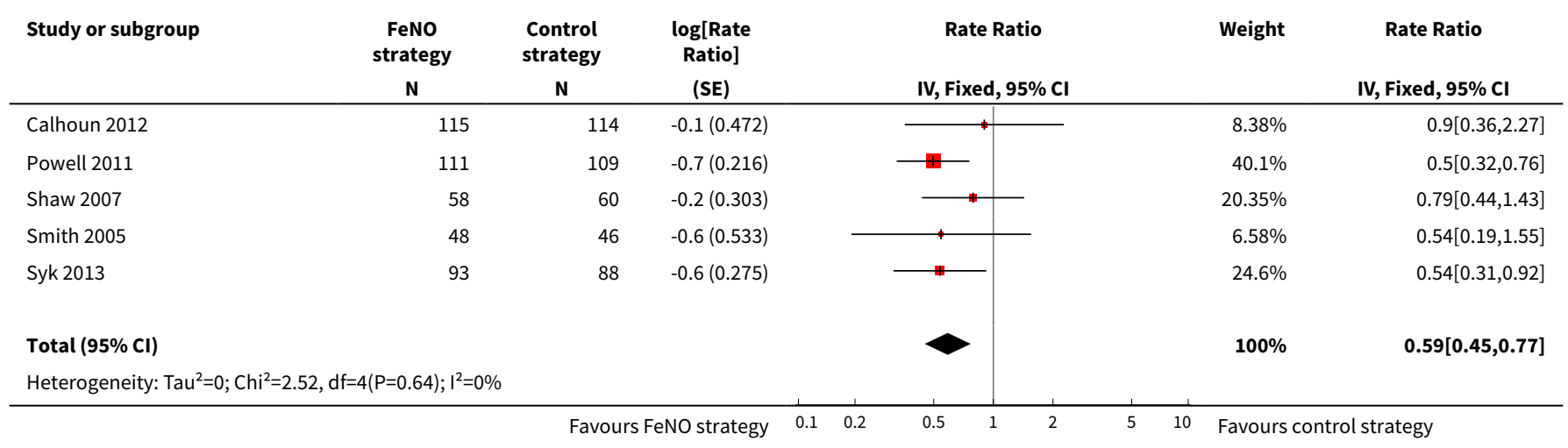




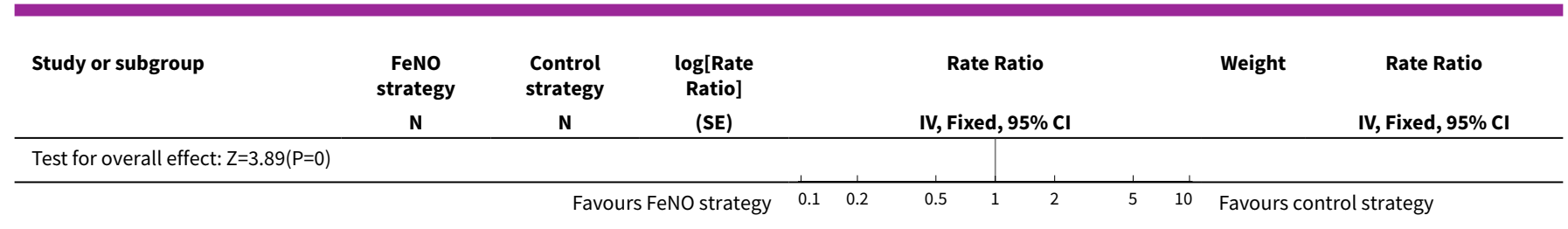

Analysis 1.3. Comparison 1 Asthma treatment tailored on FeNO versus clinical symptoms, Outcome 3 Severe exacerbations requiring oral corticosteroids.

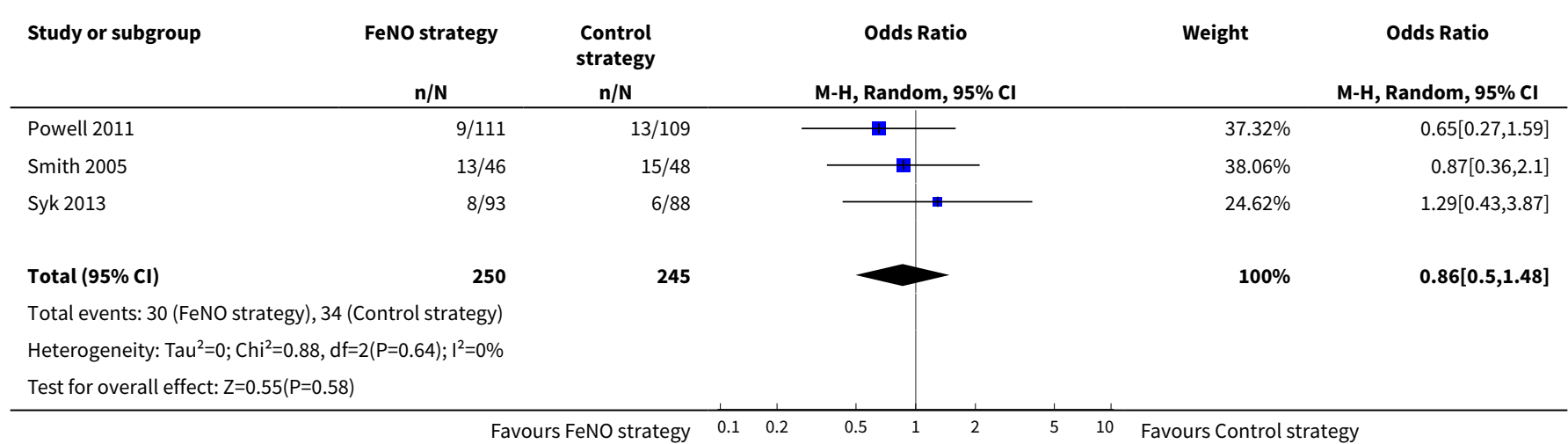

Analysis 1.4. Comparison 1 Asthma treatment tailored on FeNO versus clinical symptoms, Outcome 4 Severe exacerbations requiring hospitalisation.

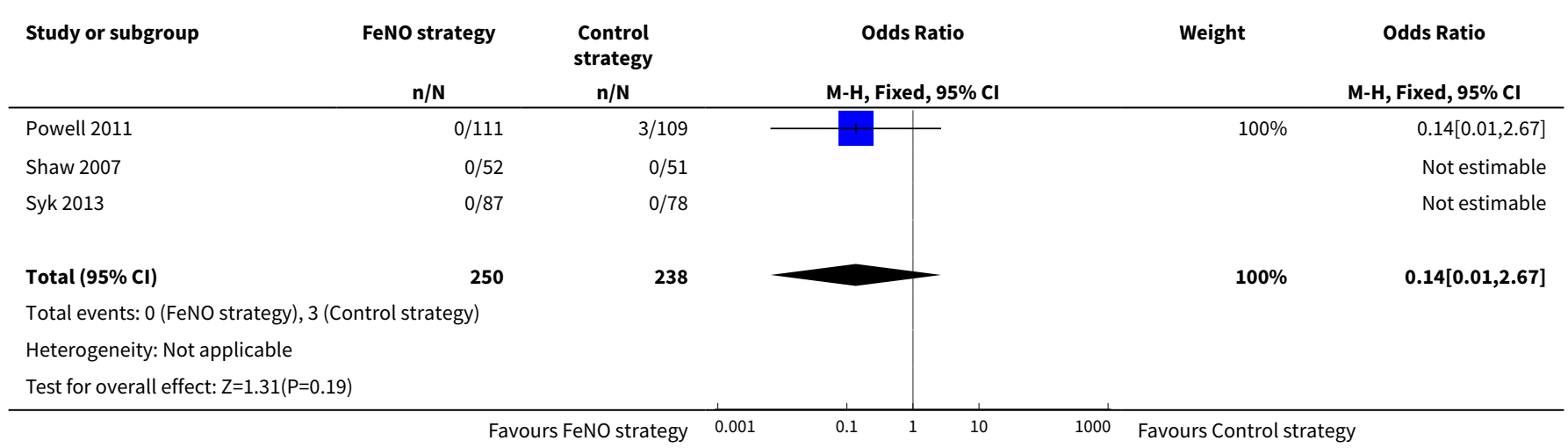

Analysis 1.5. Comparison 1 Asthma treatment tailored on FeNO versus clinical symptoms, Outcome $5 \mathrm{FEV}_{1} \%$ pred at final visit.

\begin{tabular}{|c|c|c|c|c|c|c|}
\hline Study or subgroup & $\begin{array}{c}\text { FeNO } \\
\text { strategy } \\
\mathbf{N} \\
\end{array}$ & $\begin{array}{c}\text { Control } \\
\text { strategy } \\
\text { N }\end{array}$ & $\begin{array}{l}\text { Mean Dif- } \\
\text { ference } \\
\text { (SE) }\end{array}$ & $\begin{array}{l}\text { Mean Difference } \\
\text { IV, Fixed, } 95 \% \mathrm{CI}\end{array}$ & Weight & $\begin{array}{l}\text { Mean Difference } \\
\text { IV, Fixed, } 95 \% \mathrm{CI}\end{array}$ \\
\hline Honkoop 2014 & 189 & 203 & $0(0.735)$ & - & $76.29 \%$ & $0.04[-1.4,1.48]$ \\
\hline Powell 2011 & 73 & 78 & $0.2(1.902)$ & & $11.38 \%$ & $0.19[-3.54,3.92]$ \\
\hline Smith 2005 & 46 & 48 & $3.8(4.233)$ & & $2.3 \%$ & $3.8[-4.5,12.1]$ \\
\hline
\end{tabular}




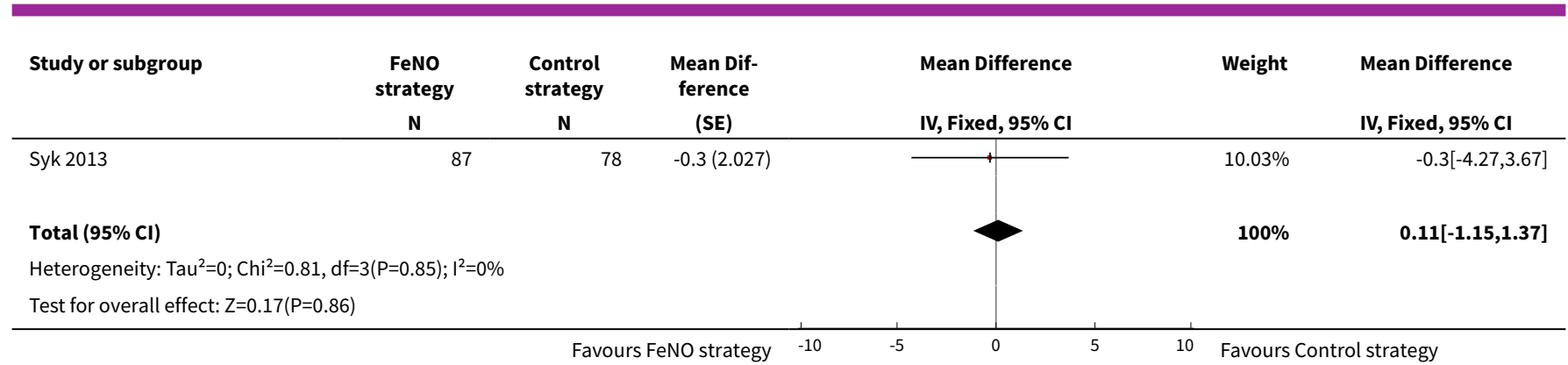

Analysis 1.6. Comparison 1 Asthma treatment tailored on FeNO versus clinical symptoms, Outcome 6 FeNO level at final visit.

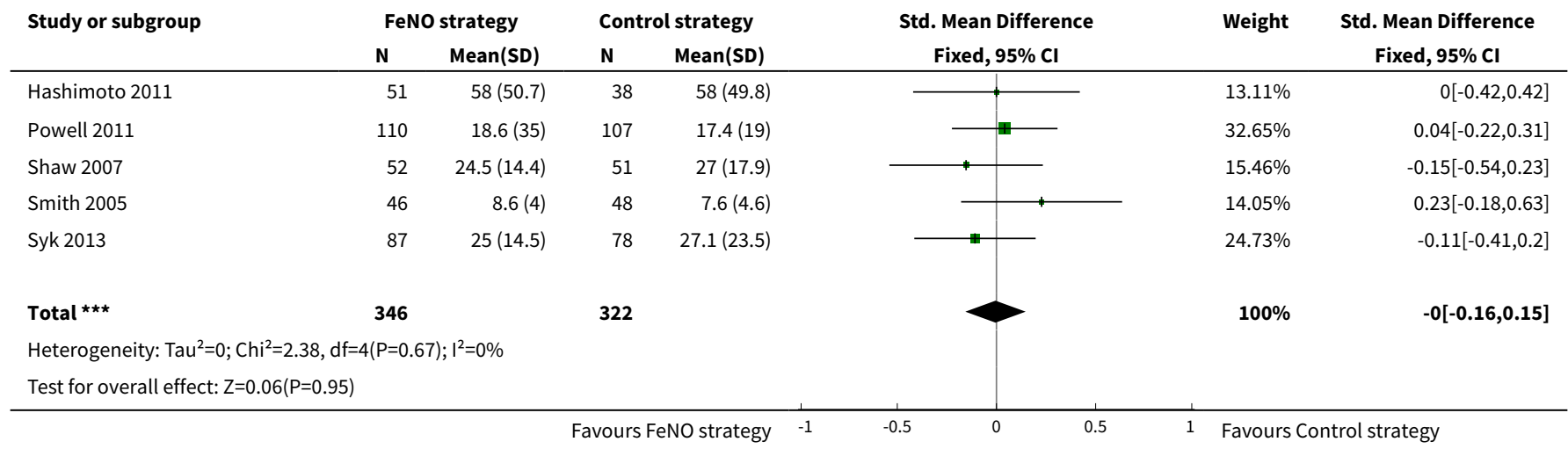

Analysis 1.7. Comparison 1 Asthma treatment tailored on FeNO versus clinical symptoms, Outcome 7 Symptom score as per Asthma Control Test.

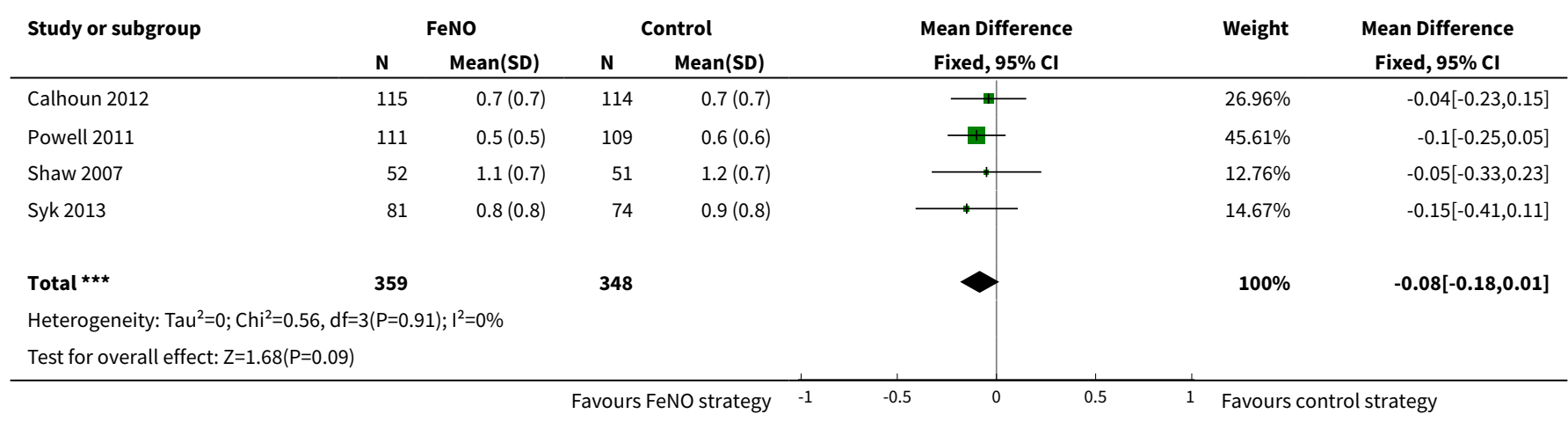


Analysis 1.8. Comparison 1 Asthma treatment tailored on FeNO versus clinical symptoms, Outcome 8 Symptom score as per AQLQ.

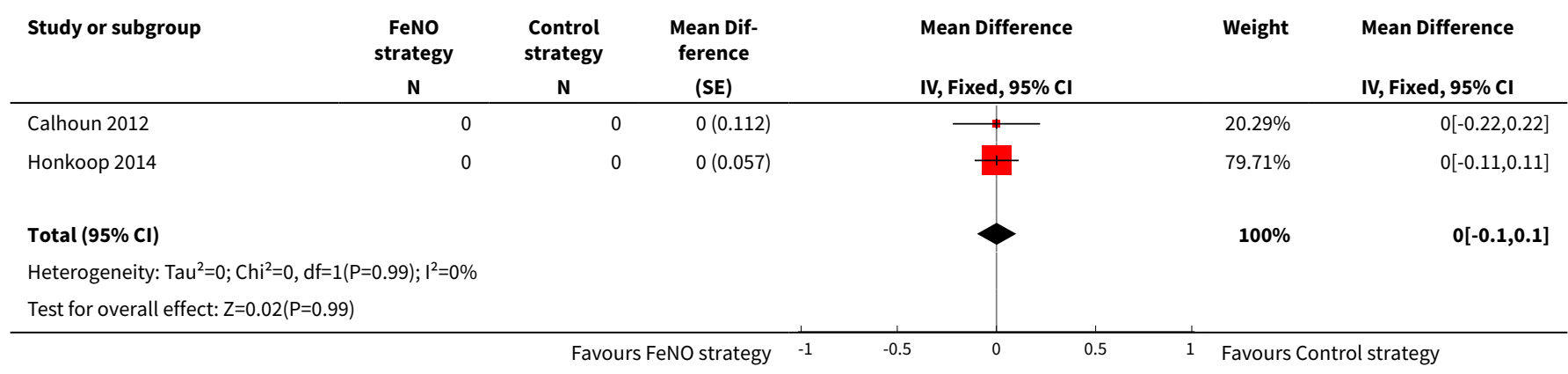

Analysis 1.9. Comparison 1 Asthma treatment tailored on FeNO versus clinical symptoms, Outcome 9 ICS dose at final visit (microgram per day).

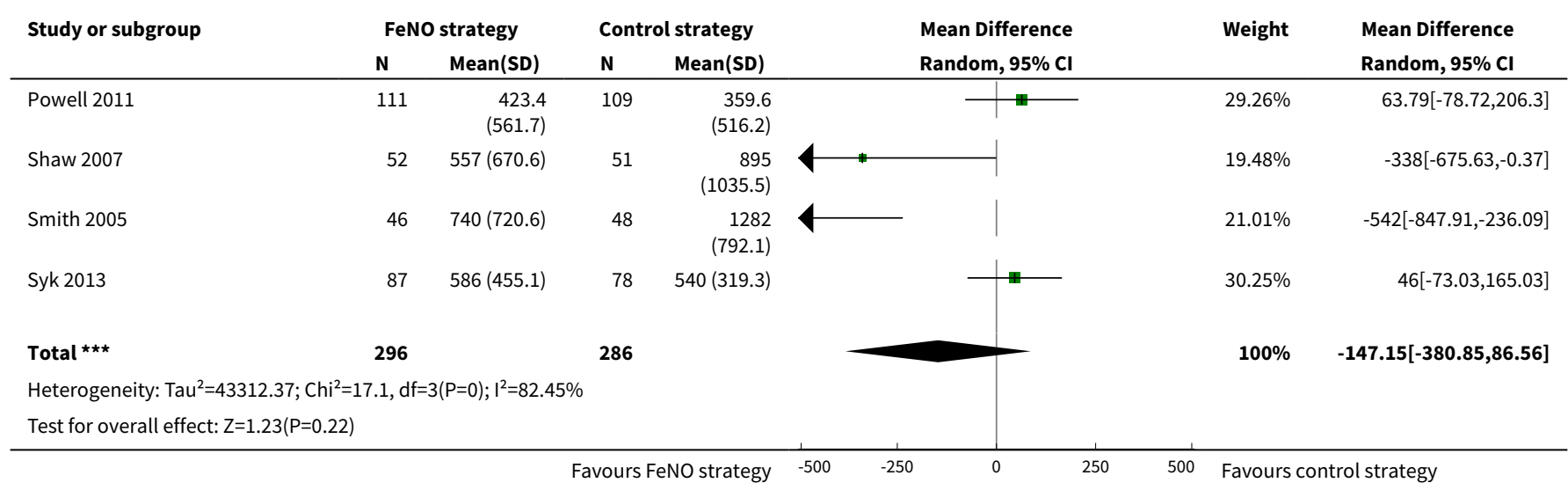

Analysis 1.10. Comparison 1 Asthma treatment tailored on FeNO versus clinical symptoms, Outcome 10 Subgroup (control guideline use): Number of participants who had $\geq 1$ exacerbations over study period.

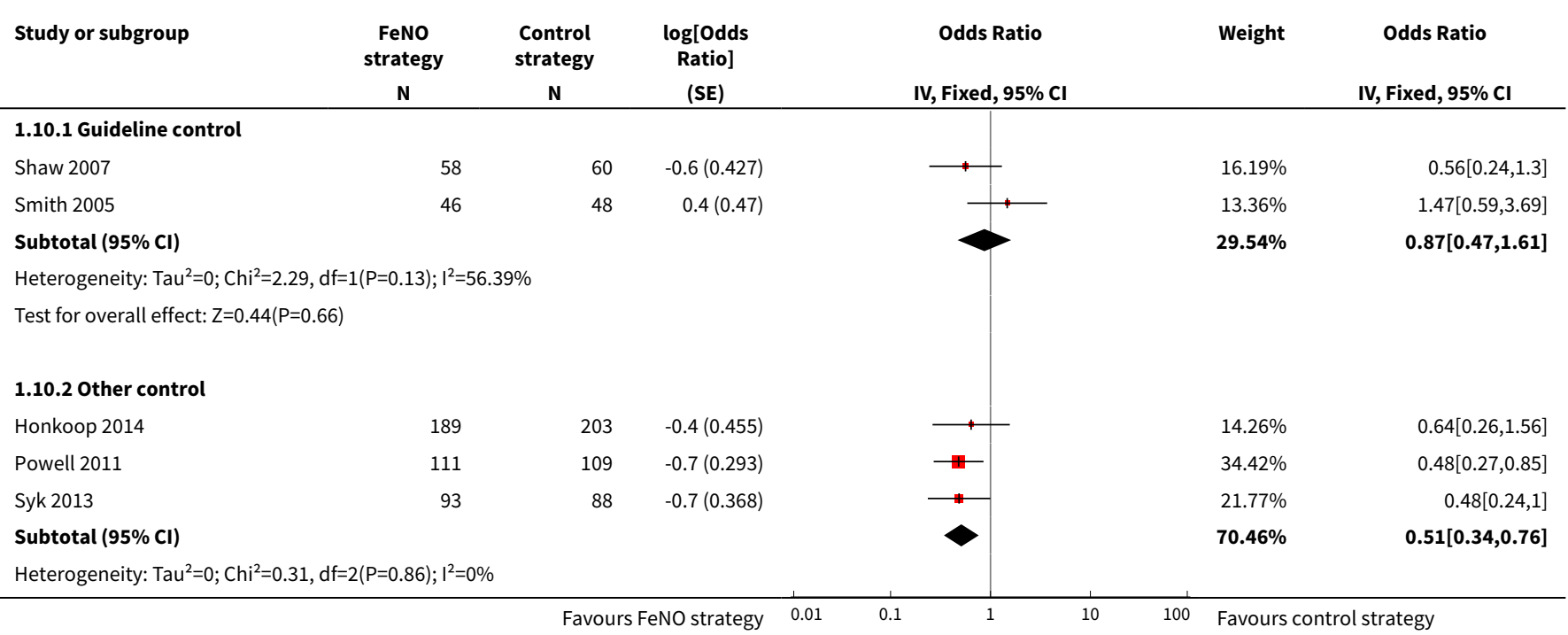




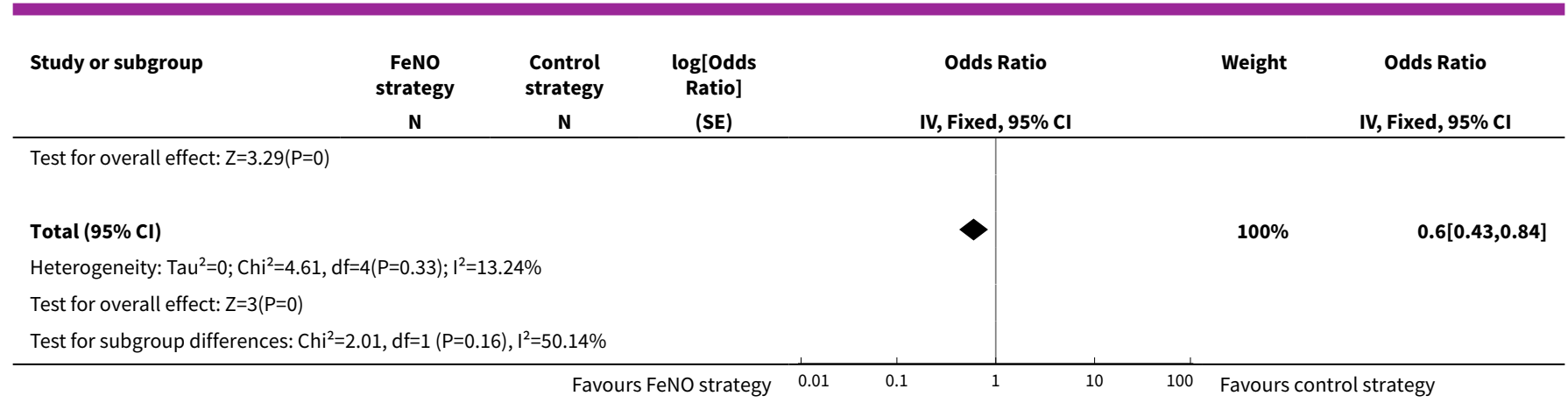

\section{Analysis 1.11. Comparison 1 Asthma treatment tailored on FeNO versus clinical symptoms, Outcome 11 Subgroup (control guideline use): Number of exacerbations per 52 weeks (exacerbation rates).}

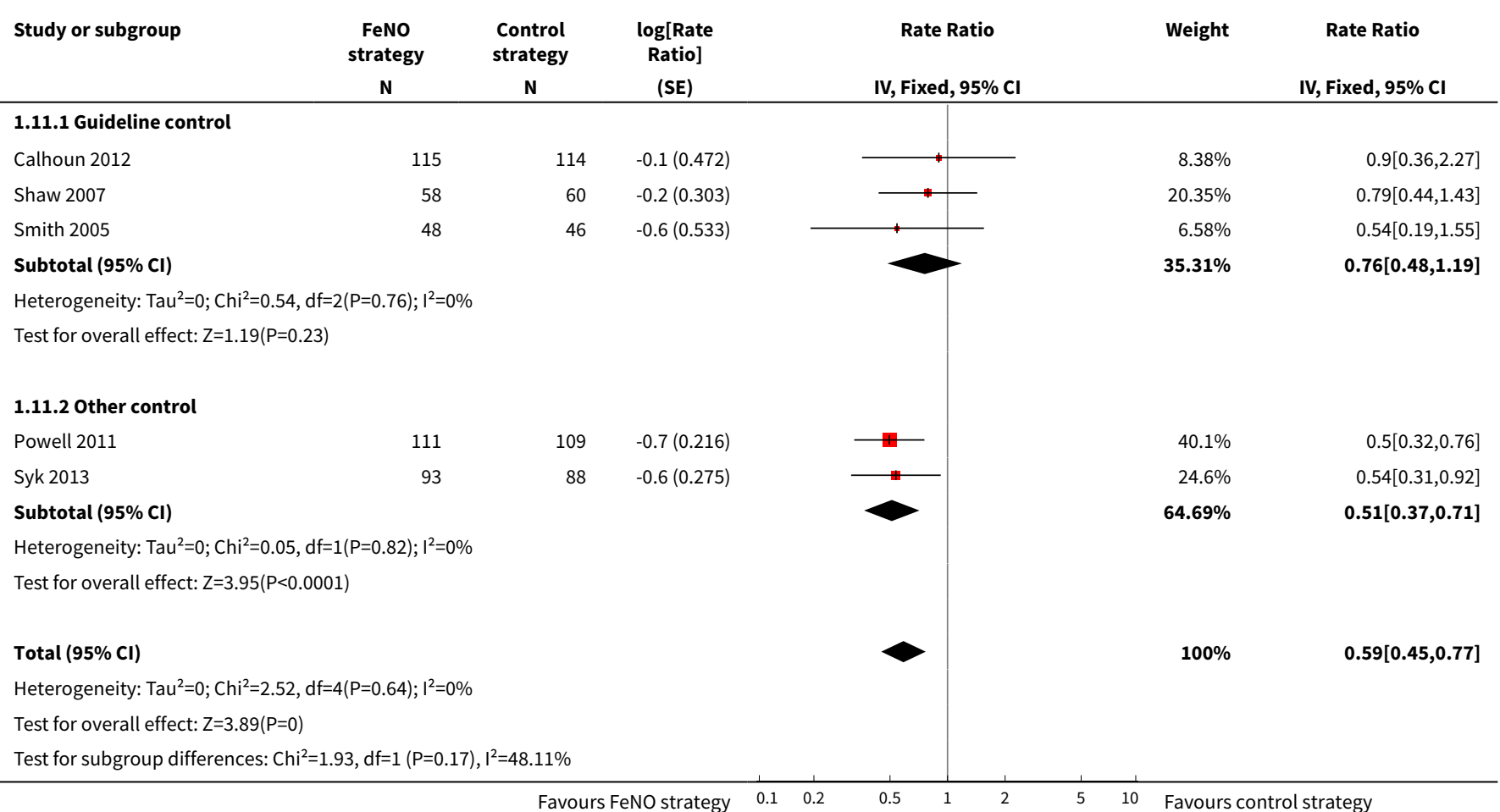

\section{ADDITIONAL TABLES}

Table 1. Included studies definitions

\begin{tabular}{lllll}
\hline Study ID & Exacerbation definition & FeNO cutoff (ppb) & $\begin{array}{l}\text { Symptom strate- } \\
\text { gy }\end{array}$ & Duration \\
\hline Calhoun 2012 & $\begin{array}{l}\text { Increased asthma symptoms resulting in } \\
\text { use of oral corticosteroids, increased ICS, } \\
\text { or additional asthma medications }\end{array}$ & 22 to 35 maintain & $\begin{array}{l}\text { <2 decrease } \\
\text { Heart, Lung, and } \\
\text { Blood Institute } \\
\text { guidelines }\end{array}$ \\
\hline
\end{tabular}


Table 1. Included studies definitions (Continued)

\begin{tabular}{|c|c|c|c|c|}
\hline Hashimoto 2011 & $\begin{array}{l}\text { Decrease in morning } \mathrm{FEV}_{1}>10 \% \text { compared } \\
\text { to mean } \mathrm{FEV}_{1} \text { from week before, increase } \\
\text { in symptoms requiring increased pred- } \\
\text { nisolone }>10 \mathrm{mg} / \text { day, or course of antibi- } \\
\text { otics, regardless of hospitalisations }\end{array}$ & $\begin{array}{l}>+10 \text { ppb \& }>10 \% \text { in- } \\
\text { crease } \\
>+10 \text { ppb } \& \leq 10 \% \\
\text { maintain } \\
\text { minus } \geq 10 \& \leq 10 \text { main- } \\
\text { tain } \\
<-10 \text { ppb decrease }\end{array}$ & $\begin{array}{l}\text { Based on Global } \\
\text { Initiative for Asth- } \\
\text { ma (GINA) guide- } \\
\text { lines for treatment } \\
\text { of severe asthma }\end{array}$ & 6 months \\
\hline Honkoop 2014 & $\begin{array}{l}\text { Severe exacerbations defined as hospital- } \\
\text { isation, emergency department visit be- } \\
\text { cause of asthma, or use of oral corticos- } \\
\text { teroids for } 3 \text { or more days }\end{array}$ & $\begin{array}{l}<25 \text { decrease } \\
25 \text { to } 50 \text { no change } \\
>50 \text { increase }\end{array}$ & $\begin{array}{l}\text { Asthma Con- } \\
\text { trol Test, } 7 \text { items } \\
\text { which includes } \\
\text { lung function }\end{array}$ & 12 months \\
\hline Powell 2011 & $\begin{array}{l}\text { Events for which the participant sought } \\
\text { medical attention (unscheduled doctor } \\
\text { visit, emergency department visit, hos- } \\
\text { pital admission, or when oral corticos- } \\
\text { teroids were used to treat increase in asth- } \\
\text { ma symptoms) }\end{array}$ & $\begin{array}{l}<16 \text { decrease } \\
16 \text { to } 29 \text { maintain } \\
>29 \text { increase }\end{array}$ & $\begin{array}{l}\text { Asthma Control } \\
\text { Test }\end{array}$ & 4 months \\
\hline Shaw 2007 & $\begin{array}{l}\text { Increasing asthma symptoms requiring } \\
\text { course of oral steroids or antibiotics }\end{array}$ & $\begin{array}{l}<16 \text { once or } 16 \text { to } 26 \\
\text { second decrease } \\
>26 \text { increase }\end{array}$ & $\begin{array}{l}\text { BTS and Asthma } \\
\text { Control Test }\end{array}$ & 12 months \\
\hline Smith 2005 & $\begin{array}{l}\text { Minor exacerbation: global daily asthma } \\
\text { score of } 2 \text { on } \geq 2 \text { consecutive days } \\
\text { Major exacerbation: global daily asthma } \\
\text { score of } 3 \text { on } \geq 2 \text { consecutive days }\end{array}$ & $\begin{array}{l}<15 \text { maintain } \\
\geq 15 \text { increase } \\
(250 \mathrm{~mL} / \mathrm{sec})\end{array}$ & GINA guidelines & $\begin{array}{l}12 \text { months } \\
\text { (Phase } 2 \text { ) }\end{array}$ \\
\hline Syk 2013 & $\begin{array}{l}\text { Increasing symptoms requiring a course of } \\
\text { oral corticosteroids }\end{array}$ & $\begin{array}{l}\text { Women } \\
<19 \text { decrease step } \\
19 \text { to } 23 \text { maintain } \\
\geq 24 \text { increase } 1 \text { step } \\
\geq 30 \text { increase } 2 \text { steps } \\
\text { Men } \\
<21 \text { decrease step } \\
21 \text { to } 25 \text { maintain } \\
\geq 26 \text { increase } 1 \text { step } \\
\geq 32 \text { increase } 2 \text { steps }\end{array}$ & $\begin{array}{l}\text { Based on pa- } \\
\text { tient-reported } \\
\text { symptoms, SABA } \\
\text { use, physical ex- } \\
\text { amination, and } \\
\text { spirometry results }\end{array}$ & 12 months \\
\hline
\end{tabular}

FeNO: fractional exhaled nitric oxide

FEV1: forced expiratory volume in 1 second

ICS: inhaled corticosteroids

SABA: short-acting beta-agonist 


\section{APPENDICES}

\section{Appendix 1. Sources and search methods for the Cochrane Airways Group Specialised Register (CAGR)}

\section{Electronic searches: core databases}

\begin{tabular}{ll}
\hline Database & Frequency of search \\
\hline CENTRAL (the Cochrane Library) & Monthly \\
\hline MEDLINE (Ovid) & Weekly \\
\hline EMBASE (Ovid) & Weekly \\
\hline PSyCINFO (Ovid) & Monthly \\
\hline CINAHL (EBSCO) & Monthly \\
\hline AMED (EBSCO) & Monthly \\
\hline
\end{tabular}

\section{Handsearches: core respiratory conference abstracts}

\begin{tabular}{ll}
\hline Conference & Years searched \\
\hline American Academy of Allergy, Asthma and Immunology (AAAAI) & 2001 onwards \\
\hline American Thoracic Society (ATS) & 2001 onwards \\
\hline Asia Pacific Society of Respirology (APSR) & 2004 onwards \\
\hline British Thoracic Society Winter Meeting (BTS) & 2000 onwards \\
\hline Chest Meeting & 2003 onwards \\
\hline European Respiratory Society (ERS) & $1992,1994,2000$ onwards \\
\hline International Primary Care Respiratory Group Congress (IPCRG) & 2002 onwards \\
\hline Thoracic Society of Australia and New Zealand (TSANZ) & 1999 onwards \\
\hline
\end{tabular}

\section{MEDLINE search strategy used to identify trials for the CAGR}

\section{Asthma search}

1. exp Asthma/

2. asthma\$.mp.

3. (antiasthma\$ or anti-asthma\$).mp.

4. Respiratory Sounds/

5. wheez\$.mp. 
6. Bronchial Spasm/

7. bronchospas\$.mp.

8. (bronch\$ adj3 spasm\$).mp.

9. bronchoconstrict\$.mp.

10. exp Bronchoconstriction/

11. (bronch\$ adj3 constrict\$).mp.

12. Bronchial Hyperreactivity/

13. Respiratory Hypersensitivity/

14. ((bronchial\$ or respiratory or airway\$ or lung\$) adj3 (hypersensitiv\$ or hyperreactiv\$ or allerg\$ or insufficiency)).mp.

15. ((dust or mite\$) adj3 (allerg\$ or hypersensitiv\$)).mp.

16. or/1-15

\section{Filter to identify RCTs}

1. exp "clinical trial [publication type]"/

2. (randomised or randomised).ab,ti.

3. placebo.ab,ti.

4. dt.fs.

5. randomly.ab,ti.

6. trial.ab,ti.

7. groups.ab,ti.

8. or/1-7

9. Animals/

10. Humans/

11.9 not (9 and 10)

12. 8 not 11

The MEDLINE strategy and RCT filter are adapted to identify trials in other electronic databases.

Appendix 2. Search strategy to identify relevant trials from the CAGR

\#1 AST:MISC1

\#2 MeSH DESCRIPTOR Asthma Explode All

\#3 asthma*:ti,ab

\#4 \#1 or \#2 or \#3

\#5 MeSH DESCRIPTOR Nitric Oxide

\#6 nitric* NEXT oxide*

\#7 FeNO

\#8 eNO

\#9 "airway inflammation" 
\#10 "exhaled NO"

\#11 biomarker*:ti,ab

\#12 \#5 or \#6 or \#7 or \#8 or \#9 or \#10 or \#11

$\# 13 \# 4$ and \#12

[Note: in search line \#1, MISC1 denotes the field in which the reference has been coded for condition, in this case, asthma]

\section{Appendix 3. Search strategy to identify relevant trials from ClinicalTrials.gov and WHO trials portal}

"exhaled nitric oxide" AND "asthma" AND "clinical trials"

\section{CONTRIBUTIONS OFAUTHORS}

All review authors reviewed the manuscript. HP and KK extracted the data and performed the analysis. HP and AC wrote the manuscript.

\section{DECLARATIONSOF INTEREST}

Some of the review authors (HP, AC, CT) have conducted a randomised controlled trial in children on this subject.

KK: none known

\section{SOURCES OF SUPPORT}

\section{Internal sources}

- Children's Hospital Foundation, Australia.

Support for research team to which AC \& HP belong

- Kayleigh Kew, UK.

Supported by St George's, University of London

\section{External sources}

- National Health and Medical Research Council, Australia.

Support for AC and post doctoral fellowship for HP through a Centre of Research Excellence

- Asthma Australia, Australia.

Early career fellowship for HP commenced in 2016

- National Institute for Health Research, UK.

This project was supported by the National Institute for Health Research (NIHR), via Cochrane Infrastructure, Cochrane Programme Grant or Cochrane Incentive funding to the Airways Group. The views and opinions expressed therein are those of the authors and do not necessarily reflect those of the Systematic Reviews Programme, NIHR, NHS, or the Department of Health.

\section{DIFFERENCES BETWEEN PROTOCOLANDREVIEW}

After retrieving articles to include in the review that reported Asthma Control Test score, we added an additional secondary outcome: symptoms of asthma as reported in Asthma Control Test.

We conducted a post hoc sensitivity analysis to remove the study that included pregnant women only (Powell 2011). 